\title{
X-ray generation using carbon nanotubes
}

\author{
Richard J Parmee ${ }^{*+}$, Clare M Collins, William I Milne and Matthew T Cole ${ }^{*+}$
}

\begin{abstract}
Since the discovery of $X$-rays over a century ago the techniques applied to the engineering of $X$-ray sources have remained relatively unchanged. From the inception of thermionic electron sources, which, due to simplicity of fabrication, remain central to almost all X-ray applications, there have been few fundamental technological advances. However, with the emergence of ever more demanding medical and inspection techniques, including computed tomography and tomosynthesis, security inspection, high throughput manufacturing and radiotherapy, has resulted in a considerable level of interest in the development of new fabrication methods. The use of conventional thermionic sources is limited by their slow temporal response and large physical size. In response, field electron emission has emerged as a promising alternative means of deriving a highly controllable electron beam of a well-defined distribution. When coupled to the burgeoning field of nanomaterials, and in particular, carbon nanotubes, such systems present a unique technological opportunity. This review provides a summary of the current state-of-the-art in carbon nanotube-based field emission X-ray sources. We detail the various fabrication techniques and functional advantages associated with their use, including the ability to produce ever smaller electron beam assembles, shaped cathodes, enhanced temporal stability and emergent fast-switching pulsed sources. We conclude with an overview of some of the commercial progress made towards the realisation of an innovative and disruptive technology.
\end{abstract}

Keywords: X-ray; Field emission; Electron source; Carbon nanotubes; Carbon nanofibres; Nano carbons; Screen printing; Electrophoresis; Vacuum filtration; Chemical vapour deposition; Tomosynthesis; Micro focal

\section{Introduction}

Since the discovery of X-rays in 1895 [1], X-ray analysis and diagnostics have been some of the most widely researched areas in science and engineering. In the first quarter of the last century, almost half of the Nobel prizes awarded were connected with contributions to this field. Whilst the initial discoveries created great interest towards understanding the source of this novel light, it was only a short period before the applications of this "new light" became evident. J.J. Thomson had already established their ionising nature [2] and it was recognised that X-rays had different characteristics, initially termed qualitatively as "hard", "medium" and "soft" [3]; a classification which related to the relative absorption by soft tissue and bone. Certainly even at this early phase the implications for medical diagnostics was clear. Early examples included the identification of bullets and bone fractures in wounded soldiers. This resulted in a range of instruments, various densitometers,

\footnotetext{
*Correspondence: rjp89@cam.ac.uk; mtc35@cam.ac.uk

${ }^{\dagger}$ Equal contributors

Department of Engineering, Electrical Engineering Division, Cambridge University, Cambridge CB3 OFA, UK
}

chiroscopes and osteoscopes [4]. Soon thereafter this lead to the analysis of the diagnostic capabilities and therapeutic benefits of this new technology [5]. The increasing importance of X-ray techniques was evident with the development of X-ray diffraction methods [6-8] which lead ultimately to evidence the structure of DNA [9]. Compton back-scattering and fluorescence provided yet another raft of valuable applications [10-13]. Nevertheless, despite the growing range of $\mathrm{X}$-ray techniques, the primary area of application of $\mathrm{X}$-rays has remained in medical diagnosis. Additionally, X-ray sources have proven important in a wide range of inspection technologies; for medical and analytical, to security and industrial quality control. As illustrated in Figure 1, X-ray sources can be applied to a wide range of applications, including materials analysis (X-ray fluorescence, X-ray diffraction), medical and dental diagnosis and treatment (transmission radiography, computed tomography, tomosynthesis, radiotherapy and bracotherapy), electronics inspection, food security, nondestructive testing, thickness and defect monitoring, pharmaceutical quality control, and international border security. Indeed, X-ray sources are ubiquitous and have

\section{穴}




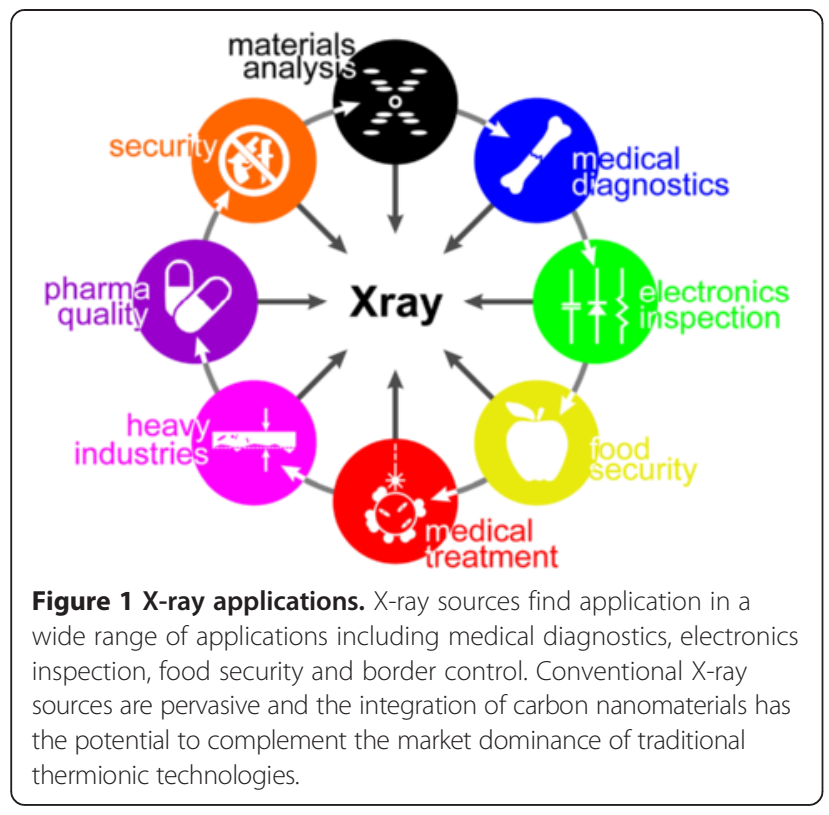

impacted on almost every area and aspect of science and industry.

The strategies for developing new X-ray sources are based on criteria driven by the needs of current applications. Despite the apparent maturity of the technology, many critical challenges remain, including; rapid beam pulsing, dose reduction, improved image contrast, and enhancement of the spatial and temporal resolution. In this review we discuss the use of carbon nanotubes (CNTs) as a platform for emerging novel field emission X-ray sources. We detail the current state-of-the-art in CNT emitter fabrication including the electron source and the gate electrode micro-fabrication, functional enhancements including reduced turn-on electric fields and enhanced stability via the incorporation of adlayers, improved X-ray beam distribution symmetry achieved through cathode shaping, micro focal sources, pulsed emission, multi-pixel sources, and miniaturisation. We conclude by providing an overview of the commercial progress to date.

\section{Review}

\subsection{Electron emission}

Fundamental to almost all commercial X-ray sources is a source of electrons. Emitted from a cathode, these electrons are directed in a high vacuum towards an anode to which a positive voltage is applied. Emission of electrons will occur from a metal surface when subjected to a high electric field. Figures 2(a) and 2(b) show examples of a commercially available thermionic X-ray sources and their mode of operation, respectively. Figure 2(c) illustrates the approximate band diagram at the metal-vacuum interface. To stimulate appreciable electron emission the electrons must either be excited from the Fermi level over the potential barrier, or tunnel through the potential barrier. This gives rise to three principle forms of electron emission; photoemission (PE), thermionic emission (TE), and field emission (FE).

PE occurs where the metal is irradiated with an optical source; where the wavelength is selected such that it defines an energy greater than the work function $(\Phi)$ of the emitter, which typically lies in the ultra violet. As a result, electrons are excited and pass over the potential barrier. PE electron sources have a low efficiency. Much of the incident optical radiation is absorbed in the bulk material of the emitter with only a small proportion of the photon population contributing to direct emission. Although PE sources have the potential to achieve extremely fast response rates, and correspondingly high bandwidths, PE has gained very little traction in most electron emission applications as only very low emission currents are possible.

In contrast, $\mathrm{TE}$ can derive appreciable current densities that are capable of stimulating X-ray emission. Figure 2(a) shows examples of static and rotating anode TE X-ray sources. Significant current densities, and consequent heating therein, necessitate rotating anode and active cooling systems in TE sources. The core components of these systems are illustrated in Figure 2(b) also outlines the principle mode of operation. Here, sealed in an inexpensive and easily fabricated evacuated glass or ceramic envelope, the electrons are liberated from a metallic filament, often made of Tungsten, which is Joule heated to in excess of $1000^{\circ} \mathrm{C}$ [14]. Since the emission is intimately dependent on the filament temperature [15] - as increasing the emitter temperature allows for much of the electron population to pass over the surface barrier - such tubes enable analogue control over the magnitude of the emission current. In TE sources this beam current is controlled by monitoring the anode current and adjusting the inferred filament temperature using a closed-loop control system. The intrinsic finite thermal inertia of the heated coil, when coupled to the lagging response of such feedback control results in a comparatively slow time response, often several hundreds of milliseconds. In addition, care must be taken to limit the filament drive current to prevent excessive power dissipation, with subsequent damage or destruction of the filament. Issues with severe electromigration can be a significant challenge. A key design functional parameter is the focal spot size, which is related, in part, to the dimensions of the electron emission area. In the case of TE sources the physical size of the filament, typically of the order of $2 \mathrm{~mm}$ in outer diameter and $10 \mathrm{~mm}$ in length. This requires the adoption of techniques to provide first order focussing. Some TE X-ray tubes are fitted with two filaments, allowing a choice of focal spot sizes, though this is at the expense of maximum available beam current and hence photon output. In order to achieve further reduction in focal spot size, electrostatic and magnetic focussing techniques are often employed, though at the expense of source complexity and size. 


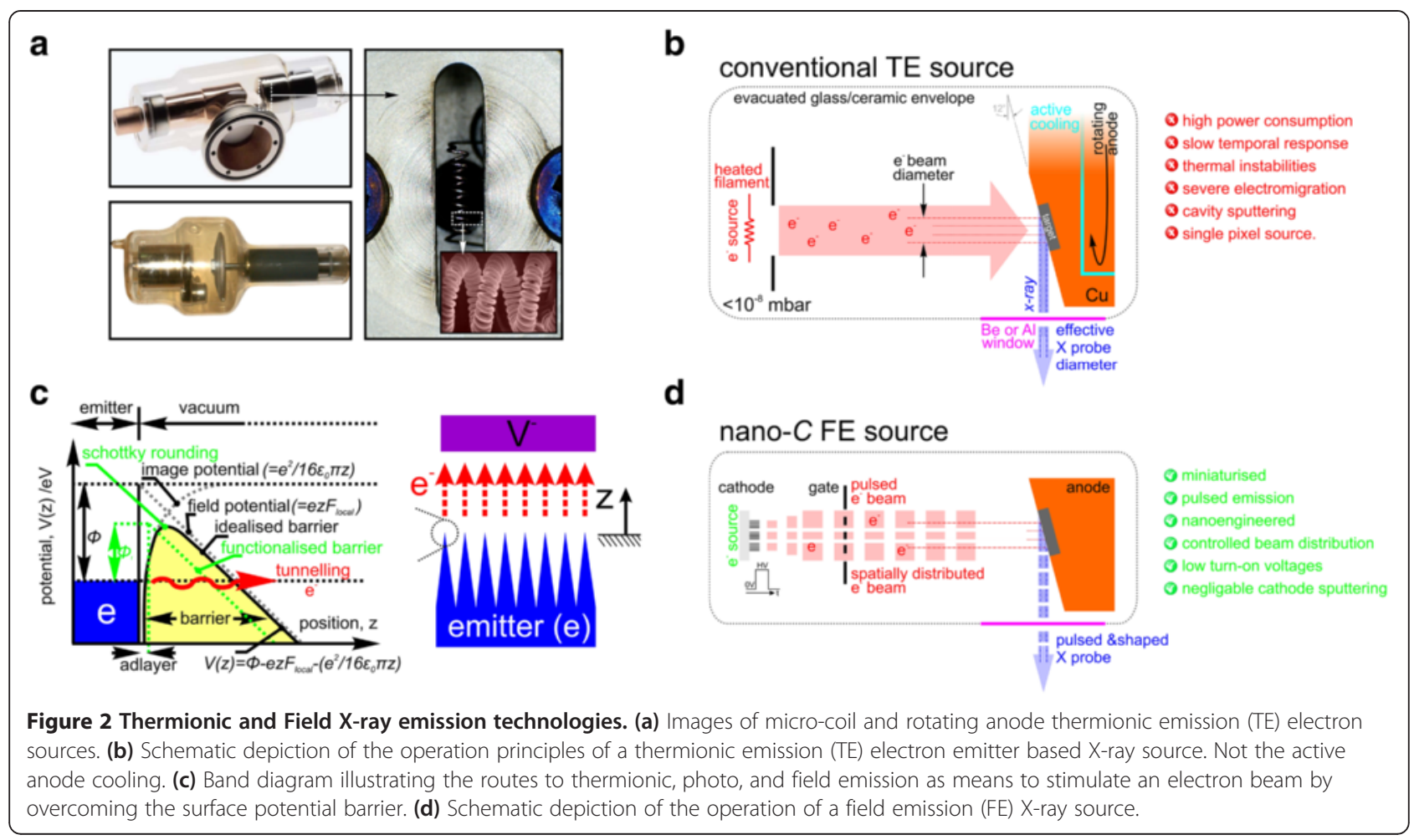

Field emission (FE) offers a number of significant benefits. Figure 2(d) illustrates a typical FE source. FE sources are often physically compact compared to their thermionic counterparts. The emission process occurs at room temperature and as such does not necessitate a direct heating element. FE is a tunnelling process and provides, as a result, near-instantaneous emission. Pulsed emission with rise times of less than $50 \mu$ s have been reported [16]. As illustrated above, electrons are emitted under the influence of a high electric field, typically of the order of a few $\mathrm{V} / \mu \mathrm{m}$. These electrons subsequently tunnel through the narrowed potential barrier. Traditionally the emission has been broadly described by Fowler-Nordheim theory [17], although this is now generally considered to be an incomplete representation in the case of electron emission from most nanomaterials. Nonetheless, a broadly accepted approximation of the field emission current, $I$, is given by;

$$
I=\left(\frac{A \beta^{2} V^{2}}{\varphi}\right) \exp \left(\frac{-B \varphi^{3 / 2}}{\beta V}\right)
$$

where $V$ is the applied voltage across the vacuum cavity, $\varphi$ is the emitter work function, $\beta$ is the field enhancement factor, and $A$ and $B$ are related to physical constants [18]. An extended analysis of the background theoretical emission mechanisms can be found in [19]. Various refinements to this model have been applied [20] to take account of the potentially elevated temperatures during emission and the extreme curvature at the nano emitters apex when whisker-like one dimensional nanomaterials are used as the field emission source. Indeed, the high electric field that is required for field emission is closely associated with the curvature and aspect ratio of the emitting material - this field enhancement factor depends upon a number of geometrical factors such as the precise form and orientation of the emitter; in general sharp whisker-like tips emit at significantly lower potentials compared to the same material that has adopted a planar morphology [21]. Such geometry-based arguments are the leading rationale for the use of high aspect ratio nanowires in field emission applications. Contrary to conventional beliefs, studies are emerging which show that the emitter morphology has a much more profound impact on reducing the turn-on and threshold electric fields compared with the effects of the emitter's work function. However, it remains challenging to attain such perturbed, high aspect ratio emitters.

Following early work by Dyke [22,23], in 1968 Spindt published details of a new method of fabricating FE arrays based on Mo conical structures. These structures were $1.5 \mu \mathrm{m}$ high with a tip radius of $50 \mathrm{~nm}[24,25]$. During the subsequent years, the use of Spindt emitters was widely adopted. They have since become common place in many electron emission systems. Spindts can be found in field emission displays [26-28] to high speed radio frequency devices $[18,29,30]$, such as travelling 
wave tubes [31,32]. Extremely high current densities of up to $20 \mathrm{~A} / \mathrm{cm}^{2}$ have been achieved [33]. Nevertheless, the issue of developing suitably high current densities with low turn-on voltages has remained an on-going challenge, principally due to demanding requirements on the emitting material. At the time, low attainable aspect ratios that Spindt emitters offered, though better than their planar counterparts, limited emitter performance. A new material capable of forming extremely high aspect ratios was required. Self-assembly via chemical vapour deposition and the emergence of nanowires and nanotubes allowed for such high aspect ratios to be fabricated over large areas. The geometry of these new emitters allowed for a corresponding amplification in the field enhancement factor and subsequent reduction in turnon voltage, typically by an order of magnitude.

Figure 3(a) summarises the various functional advantages of field emission (FE) sources over traditional TE and Schottky sources. The dashed orange circle depicts the characteristics of an ideal electron source. Figure 3(b) illustrates the mean turn-on and threshold electric fields, $E_{o n}$ and $E_{\text {th }}$ respectively, and maximum current density $\left(J_{\max }\right)$ from $\mathrm{FE}$ sources fabricated from various materials. Figure 3(b) is structured in order of increasing dimensionality (1D, 2D to 3D/bulk) where each of these dimensional classes is further organised in terms of increasing emitter work function $(\Phi)$. The mean $( \pm 1 \sigma)$ work functions are shown. Each data point was acquired over multiple studies, nominally three or more, with the figure taking into account material only. The absence of $\Phi$ errors in some of the data indicates that only one such FE study has been conducted, typically due to the recent emergence of the material in question. To extract comparable data all current densities in the considered literature where normalised relative to their maximum current densities, where this normalised value, $\mathrm{J}^{\prime}=\mathrm{J} / \mathrm{J}_{\max }$, where $0 \leq \mathrm{J}^{\prime} \leq 1$. $E_{o n}$ and $E_{\text {thr }}$ were defined as the electric field required to emit 0.1 J' and $0.3 \mathrm{~J}$ ', respectively. For clear assessment purposes of how the material type relates to efficient FE, various emitter morphologies were considered. Note that, on average, there is no clear increase in $\mathrm{J}_{\max }$ or decrease in $E_{\text {on }}$ or $E_{\text {thr }}$ with decreasing $\Phi$, as one would expect for a consistent view with earlier band arguments. Indeed, emitter geometry clearly smears out much, if not all of the functional benefits associated with the novel electronic properties of any given material. Nonetheless, the graphitic carbons are evidently largely unparalleled in their electron emission performance. Combined with the wide range of allotropes observed to date - including the zerodimensional fullerenes, the one-dimensional nanotubes and nanofibres, the two-dimensional graphenes, and threedimensional graphite - carbon truly has a morphological character perfectly matched to its impressive electronic properties.

\subsection{Field emission application of CNTs}

The discovery of carbon nanotubes (CNTs) is generally credited to Iijima in the early 1990s [134], although it is clear that there had been activity in this area for a considerable time prior to this [135]. This work, however; lead to a heightened interest which gave rise to some of the first studies on FE using CNTs in 1995 [136,137]. By the start of the following decade a range of applications had been identified to utilise these novel field emitters, including high resolution electron beam microscopes [138-141], flat panel displays [27,28,142-144], RF devices $[18,32]$, electron beam lithography [145-147] and X-ray cathode emitters [148-151]. An early review [146], provides a concise overview of the state-of-the-art prior to 2004. A detailed historical perspective on the development of CNT-based FE sources is provided in [152]. Here we provide a condensed review of the progress, as it pertains to X-ray sources, since then.

CNTs have some of the highest attainable aspect ratios, high thermal conductivity, low chemical reactivity in non-oxidising atmospheres, highly parallelised en masse fabrication, a low sputtering cross-section, a low secondary electron coefficient, and an insensitivity to direct ion-bombdarment. CNTs are becoming increasingly inexpensive with the release of new, ever larger growth reactors. However, field emitters require ultrahigh vacuum $\left(<10^{-8} \mathrm{mbar}\right)$ to provide stable operation. This limits their practical application as the material platform on which the emitters are fabricated largely dictates the tip robustness towards poor or compromised vacuum conditions which result in aggressive local ionization. In the case of the metallic Spindts, poor vacuum conditions caused tip degradation. As a result, much of the published work has been accomplished using demountable systems, which incorporate vacuum pumps to maintain the performance, although there are some notable exceptions $[153,154]$. A useful summary on this was published in 2010 [155].

It is the group of applications associated with CNTbased X-ray FE emitters [148] that is the subject of this paper, as the properties of the electron emitting CNTs offer many functional and performance advantages over conventional TE X-ray sources [156,157]. The way in which this review is structured details: shaped cathodes, micro focal sources, pulsed sources, multi-pixel sources, and miniaturised emitters. The review concludes by summarising the commercial progress to date.

Severe problems with CNT electron source fabrication, reliability, time stability, spatial uniformity, and reproducibility have beset the technology and have prevented its wide spread adoption, particularly in high beam current applications. Nevertheless, CNT-based X-ray sources were proposed following the emergence of CNTs and in 2001 Sugie et al. [148] were some of the first to describe the use of CNTs as a FE-based X-ray source. Here they grew 
(a)

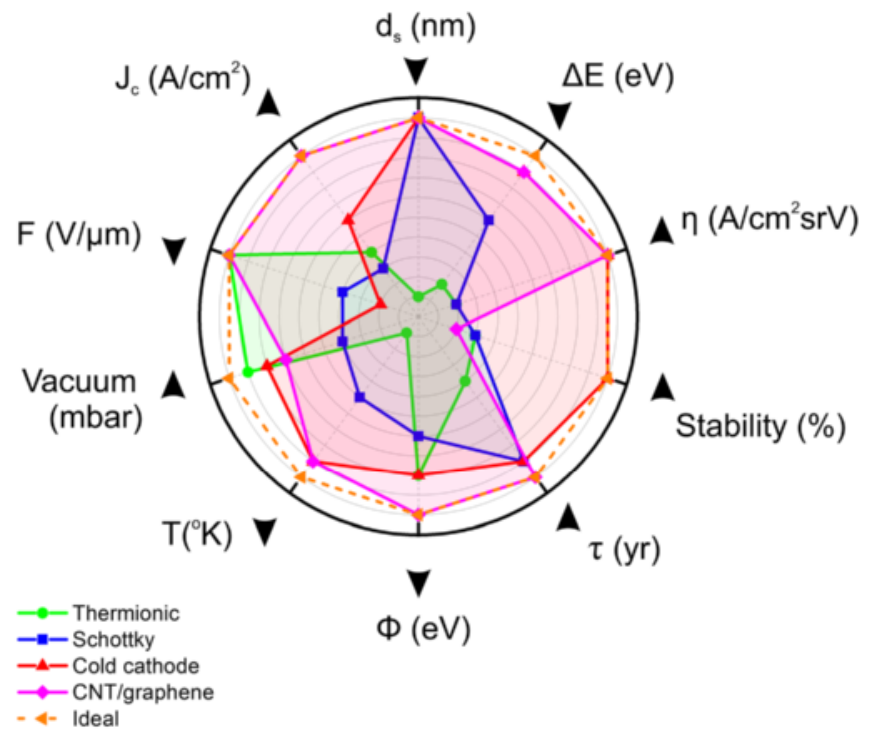

(b) FE materials

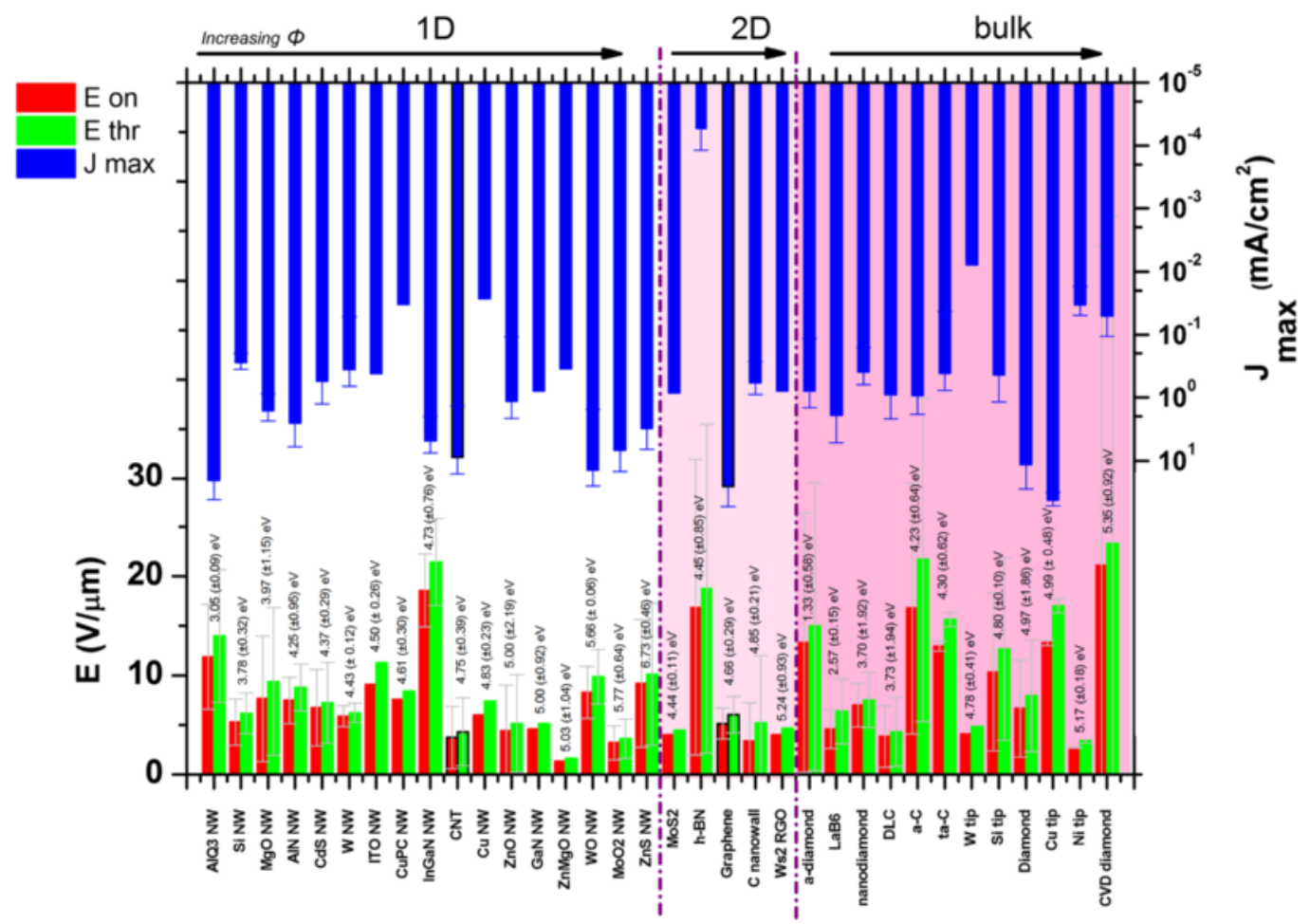

Figure 3 Comparison of common field emitting materials. (a) Polar plot for the various common-place electron emitters. CNT and graphene based field emitters out-perform such sources across most metrics, where $J_{\max }$ the current density, $E_{\text {on }}$ is the turn-on electric field, Vacuum' denotes the operating vacuum, $T$ the typical operating temperature, $\Phi$ the emitter work function, $\tau$ the lifetime, 'Stability' is the temporal stability, $\eta$ the electron-optical brightness, $\Delta E$ the energy spread of the emitted electrons, $d_{s}$ the virtual source size. Adapted from [34]. (b) Overview of the on and threshold electric fields ( $E_{\text {on }}$ and $E_{t h r}$, respectively) and maximum current density, $J_{\max }$, for various materials used for field emission to date, in order of dimensionality (1D, $2 \mathrm{D}$ and bulk) and increasing work function $(\Phi)$, including $1 \mathrm{D}$ nanowires - $\mathrm{AlQ}_{3}$ [35,36], Si [37-39], MgO [40,41], AlN [42-45], CdS [46-49], W [50-52], ITO [53], CuPC [54,55], InGaN [56-58], CNTs [59-63] Cu [64-66], ZnO [67-72], GaN [73,74], ZnMgO [70,75], WO [76-79] ), MoO2 [80-82], and ZnS [37,83] -, the 2D platelets - MoS 2 [84], h-BN [85-88], graphene [89-97], C nanowall [98-100], WS 2 RGO [101] -, and the bulk materials - a-diamond [71,102], LaB6 [103-106], nanodiamond [107,108], DLC [109,110], a-C [111-113], ta-C [114-116], W [117], Si [118-120], diamond [121-125], Cu [65,66,126], Ni [127-130], and CVD diamond [112,131-133]. 
vertically aligned forests of CNTs on Co coated W wire, with the electron beam controlled by a counter electrode mounted $0.5 \mathrm{~mm}$ from the emitter. This setup produced a beam current of just $1.5 \mu \mathrm{A}$, but was sufficient to image onto an X-ray sensitive film a range of samples including integrated circuits. The lifetime of the cathode assembly was little more than one hour and the images exhibited severe noise artefacts. Nevertheless, this work did convincingly demonstrate the potential of CNTs in X-ray applications whilst simultaneously highlighting critical functional issues such as fluctuations in emitted beam current that needed to be addressed. Another early example of a functioning X-ray tube was produced by Haga et al. [150]. Catalytically synthesised CNTs and carbon nanofibres (CNFs) grown on a Pd wire were used as the FE source, although there was no counter electrode, or gate used to extract the electron beam. This device operated for several hours at $30 \mathrm{kV}$ with a beam current of $50 \mu \mathrm{A}$. Clear images were acquired, though requiring a long and technologically unacceptable integration time of the order of minutes. The same group produced a triode-configuration (incorporating a gate electrode) which increased the beam current to about $1 \mathrm{~mA}$ [151]. Many more examples have now been published on the use of similar triode configurations [149,158-161]. These include designs with additional focusing electrodes for a micro focal imaging system operating at $18 \mathrm{kV}$, developed utilising 3D beam simulation tools [158].

\subsection{Cathode fabrication}

All X-ray tubes require the generation of a beam of electrons. This electron beam is directed towards the anode, which subsequently liberates X-rays when impacted. It is the cathode assembly that provides the source of electrons and it is the cathode design and materials which dramatically influences the resultant performance. The commercial field of vacuum electronics is now well established and was initially based on Spindt-like emitters, a comprehensive review on which is provided by Temple et al. [162]. The incorporation of CNTs within the cathode is the focus of this review as it is currently the subject of intense research in an attempt to enhance the electron emission, and hence, X-ray emission performance.

The first FE emitters using one-dimensional carbon allotropes were based on CNFs deposited on metallic tips $[146,148,150,163]$. These sought to enhance the native emission characteristics of the conventional tips by depositing CNFs, generally by CVD. Subsequent developments, however; centered on the use of planar substrates in attempts to realise more reproducible devices applicable to a wider range of electron emission applications. CNTs may be deposited on the cathode assembly using several different processes [164]. Figure 4 summarises these.

CNT thin films are readily patterned using a variety of techniques. There are numerous aspects which are yet to be well developed in the literature. Nevertheless, the attainable pattern resolution is intimately related to the orientation of the constituent CNTs within the thin film and the patterning technique employed. Aligned CNTs give higher resolution than misaligned CNTs. Wet processed thin films - such as dropped, cast, vacuum filtrated, sprayed, and screen printed - are fundamentally wet chemistry deposition techniques that can be patterned by either post deposition etching or shadow

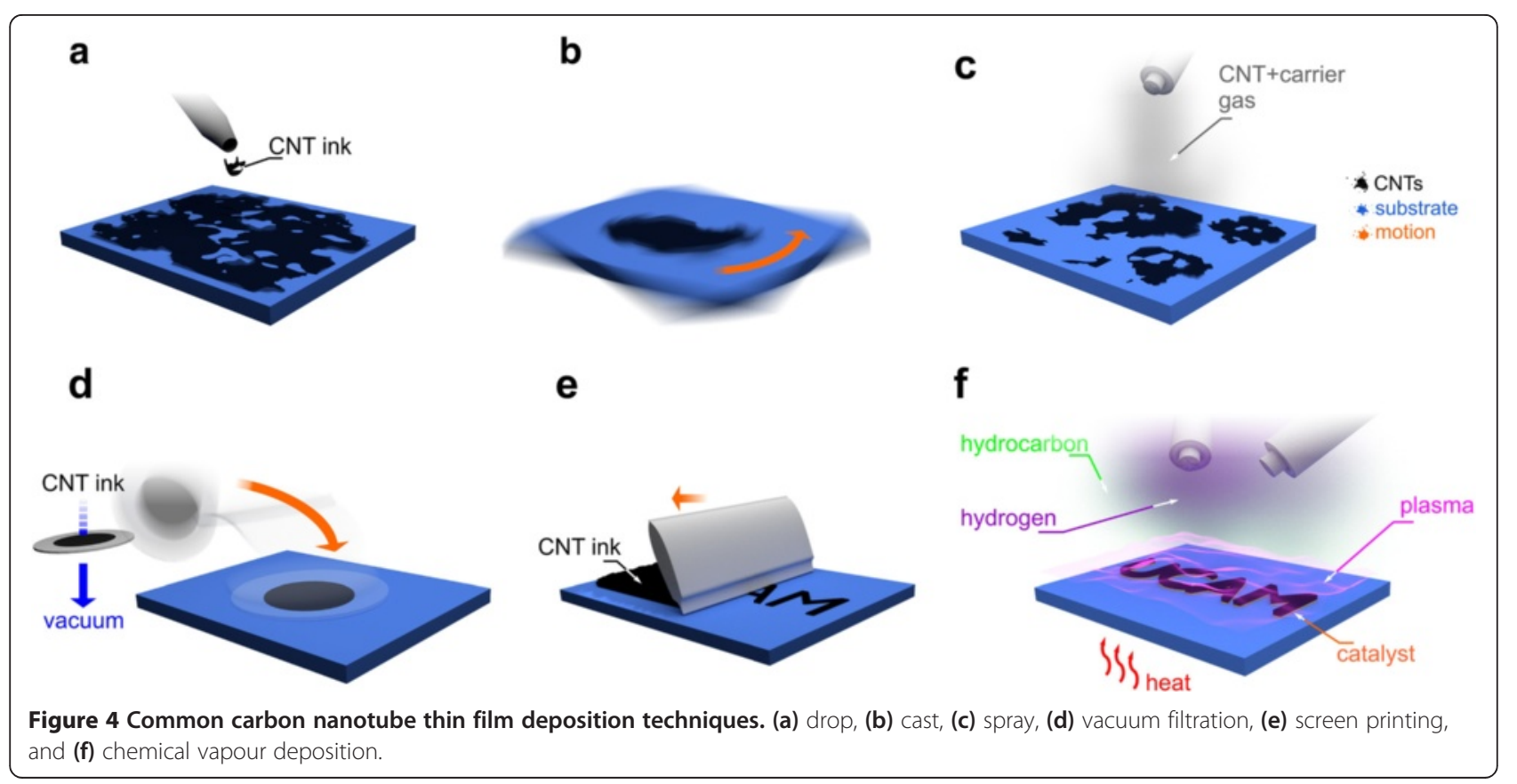


masking to protect zones from being coated with the $\mathrm{CNT}$ inks during the deposition process. These shadow approaches provide a modest maximum resolution of around $100 \mu \mathrm{m}$ as the inks often bleed beneath the masking layer, resulting in diffuse and uncontrolled edges. Without the application of external driving forces, such as magnetic or electric fields, in such patterns the CNTs are always misaligned with respect to one another. Dip pen nanolithrography and micro-ink jet printing can also be used to drop deposit CNT inks at controlled locations, with a common maximum resolution of $1 \mu \mathrm{m}$. Nevertheless, again, the CNTs are disordered and misaligned. In these additive approaches there remain significant challenges in preventing the nozzle from clogging during the deposition or the nanolithography tip becoming deformed. As a result inkjet printing and dip-pen nanolithography necessitates the use of very short CNTs, which dramatically compromises their usefulness in $\mathrm{FE}$ applications. Micro-contact printing is another additive approach to cathode patterning. Here a polymeric stamp is inked with a CNT solution and then placed in contact with a substrate which has an engineered surface hydrophobicity to ensure the CNTs adhere. Interfacial engineering marks the broadband application of this technique and often necessitates the use of self-assembled monolayers which act as adhesion promoters. Such approaches have proven useful in patterning carbon nanomaterials [165], though their spatial resolution is again limited to a few micrometers at present. In addition to the additive patterning approaches discussed, there are various subtractive means available. Most common is by way of conventional lithographically patterning the deposited CNT thin film, defining a hard mask, and oxygen plasma etching the exposed CNTs. This approach gives high resolution, typically $\leq 0.4 \mu \mathrm{m}$. Nevertheless, common to all wet chemistry approaches to CNT deposition remains the fact that the CNTs are disordered and unaligned with respect to one another.

Chemical vapour deposition (CVD) processes dramatically bolster the maximum potential resolution to around $<0.1 \mu \mathrm{m}$ by direct patterning of the physical vapour deposited catalyst whilst also allowing for the growth of individual vertically aligned CNTs. Indeed, inclusion of plasma during heating and exposure to the gaseous hydrocarbon and atomic hydrogen sources can be used to assist in the catalytic activity and alignment of the CNTs. CVD is well suited to patterning aligned CNT geometries however it is restrained, at present, to the use of high temperature $\left(>300^{\circ} \mathrm{C}\right)$ compatible substrates, such as glass, quartz, and Si.

Another important consideration when noting the various merits of the available deposition techniques is the effective roughness and area uniformity achieved. The various deposition techniques produce films of varying thickness uniformity. CVD far exceeds the degree of uniformity of all other techniques, followed, in rank order, by casting, vacuum filtration, screen printing, and finally spray and drop casting; the latter of which typically gives coffee-stained like thin films that have a significant spatial variation in CNT density. Indeed, CVD, as demonstrated by the group of Milne, has yielded variations in surface roughness of $<3 \%$ [166]. Nevertheless, for processing simplicity and related cost reductions rather than functional reasons, most CNT-based FE X-ray sources are based on wet chemistry processed thin films. What follows here summarises the fabrication details of some of the more common CNT thin film fabrication techniques, with particular emphasis on those that have been used in CNT-based FE X-ray sources.

\subsubsection{Drop, cast and spray}

Drop (Figure 4(a)), cast (Figure 4(b)), and spray (Figure 4(c)) approaches have proven, thus far, the fabrication method of choice by many. This is likely a direct consequence of their low cost and straightforward processing rather than any direct functional enhancements the fabrication techniques allow for. Drop, cast and spray techniques all require CNT inks. In each case, respectively, these are deposited either by direct dropping of the ink, spin coating or casting of the ink, or spray coating of the ink using a pressurised carrier gas. All these approaches initially require wet processing of the as-grown CNTs and it is this which, commonly to all, limits their usefulness and the consequent performance of the resulting X-ray source. The required high power sonication and vacuum unstable surfactants needed to form the stabilised, homogenous inks results in compromised temporal stability, deleterious hysteresis, and generally degraded emission.

\subsubsection{Electrophoresis}

Electrophoresis is a derivative of inking deposition. Electrophoresis involves the motion, placement, and potentially modest alignment of drop or spray deposited CNTs. Electrophoresis exploits the CNTs native anisotropic charge distribution and its interaction with an applied electric field $[160,167,168]$. Elsewhere it has been widely used as a means of depositing phosphor materials. It has also been applied to the deposition of bundles of SWCNTs on various substrates, such as stainless steel or doped Si [167-179]. Composite CNT films deposited by electrophoresis have been fabricated with controlled surface density with good field emission performance, current density and long-term stability under high operating voltages, which has been applied to an electron source for high-resolution X-ray imaging [160]. Wang et al. [169] deposited MWCNTs on $\mathrm{Cr} / \mathrm{Cu}$ electrodes supported on an oxidised $\mathrm{Si}$ support with a glass interlayer adhesion promoter. The emitters were 
annealed at $480^{\circ} \mathrm{C}$ for $30 \mathrm{~min}$ following deposition to mobilise the glass interlayer and reduce the effective interfacial resistance. As with other solution-based fabrication techniques, in order to reduce the emitters turn-on bias they were taped to activate them; a threshold field of $3.5 \mathrm{~V} / \mu \mathrm{m}$ was measured (for an emission current density of $10 \mu \mathrm{A} / \mathrm{cm}^{2}$ ). Though a simple and low-cost means of defining the pixel size, electrophorectially defined emission zones only allow for relatively large cathode diameters, of the order of $2 \mathrm{~mm}$, which reduces the systems functionality. Calderón-Colón et al. [160] employed photolithography and liquid phase electrophoretic deposition to pattern disordered and unaligned MWCNTs in a homogenous solution with $\mathrm{MgCl}_{2}$ and glass frits. Here the film thickness was broadly controlled by the deposition time and the magnitude of the applied voltage, though accurate sampleto-sample reproducibility and control over the thickness, to $<10 \mathrm{~nm}$ surface roughness, is challenging. Such techniques are comparatively low in uniformity and reproducibility, a direct consequence of the simple macro scale processing. Moreover, the common binder matrices are far from pure, making elucidation of the underlying emission mechanisms somewhat challenging, though nonetheless functional. Indeed, as with all other inking deposition techniques, the emitters do require mechanical activation for the cathodes to be of any practical use, though electrophoretic patterning is indeed rapid and simple to implement.

\subsubsection{Vacuum filtration \& screen printing}

Many of the FE X-ray sources demonstrated have employed screen printed or vacuum filtrated CNT thin films [156,169-171] (Figure 4(d)). Here CNT solutions are deposited at the macro-scale and form highly disordered, nominally planar, spaghetti-like networks with but a few individual CNTs standing upright, at many unregistered angles relative to one another. In the case of vacuum filtration the CNT ink is poured onto a porous mixed (nitro) cellulose ester membrane, which has a partial vacuum applied on its opposite side. Such porous membranes have controlled apertures, typically around $0.2 \mu \mathrm{m}$ in diameter. The reduced pressure stimulates the solvent within the CNT ink to pass through the membrane, whilst the membrane stops the CNTs from passing. Once the ink reservoir is depleted the thin film is rinsed with de-ionised water to remove much of the deleterious surfactants, leaving a thin CNT film on the membrane. Note, however; that much of the surfactant still remains even after extensive rinsing using deionised water. The CNT thin film can then be transferred to an arbitrary acetone-resistant substrate by applying modest pressure $\left(40 \mathrm{~g} / \mathrm{cm}^{2}\right)$ and heat $\left(\mathrm{ca} .70^{\circ} \mathrm{C}\right)$ for an extended period of time (often of the order of $3 \mathrm{~h}$ ). The membrane is then dissolved, by exposure to acetone or methanol, and the CNT thin film remains. The CNT film thickness, and hence sheet resistance and optical transparency, is controlled by adjusting the amount of CNT ink filtered through the membrane.

CNT thin film fabrication by vacuum filtration has been employed for more than a decade. It offers a rapid, low cost way to fabricate CNT thin films. Little to no infrastructure is required and the films can be processed rapidly, over large areas. Nonetheless, as in the case of drop, cast and spray, such chemi douche processing requires stabilised inks. CNTs experience high inter-tube van der Waals forces; they tend to agglomerate. Though this interaction has been exploited elsewhere to fabricate novel aligned nanostructured membranes [172], such agglomeration is problematic in producing homogenous CNT inks and solutions. As such, various, often sodium-based, surfactants such as sodium dodecylbenzene sulphate, sodium dodecyl sulphate, and Triton $\mathrm{X}$ are required to produce homogenous solutions with the CNTs well-dispersed throughout the solution. Further aggressive acid treatments and extended durations under high power ultrasonication significantly degrade the length, crystallinity and subsequent electronic character of the CNTs which necessarily limits the electron emission performance. These inks are then transferred to metallic disks using conventional screen printing methods or vacuum coated mixed cellulose ester membranes that are subsequently dissolved in acetone following transfer [173]. The morphology of these films is highly disordered. They typically lack high aspect ratio protrusions, resulting in poor field emission performance. FEs fabricated in this way have a number of intrinsic problems; chiefly that mechanical taping is required to activate the surfaces and enhance their field emission characteristics. Taping, using adhesive coated tape, increases the surface roughness of the CNT thin-films. It is a macro-scale process and affords very little reproducibility, Moreover; the necessary surfactants are usually vacuum unstable giving rise to emission profiles that deleteriously drift with time [170,174-176]. CNT inks can often have significant out-gassing [177] when even modestly heated, compromising the vacuum envelope. The resultant reduction in field emission performance and reduced current density has, as a result, prevented CNT-based pastes and ink from gaining commercial traction, though cathodes fabricated in this way appeal as the reduced reproducibility is off-set by the ease of fabrication. Such films are also somewhat dynamic and often have weak adhesion to the substrate. Their morphology shifts with time during the application of a high electric field due to the intrinsic torque induction within the CNTs due to the tip or root positioning of the growth catalyst particle.

To obviate issues of weak interfacial adhesion between the substrate and the CNTs, Kim et al. [154,178], using 
screen printing, as illustrated in Figure 4(e), employed ball-milled pastes combined with inorganic fillers including $\mathrm{Ag}$ and $\mathrm{Ni}$ alloyed nano-particles and oxides in an ethyl cellulose powder and terpineol solvent. No surfactants were used. The pastes were deposited on indium tin oxide coated glass substrates followed by $300^{\circ} \mathrm{C}$ postbake to remove residual solvents. The derived slurry showed strong adhesion to the substrate, good uniformity and reproducibility with a current density of up to $350 \mathrm{~mA} / \mathrm{cm}^{2}$. Nevertheless, ball-milling degrades the graphitic quality of the MWCNTs, which adversely impacts the long-term time stability relative to high quality crystalline material, although these devices did show excellent high-temperature operation (up to $800^{\circ} \mathrm{C}$ ), robustness towards harsh vacuum environments, impressive spatial uniformity, a low turn on voltage of $1 \mathrm{~V} / \mu \mathrm{m}$, and enhanced temporal stability relative to conventional CNT pastes, although the anode current was still degraded by around 30\% under DC operation over a $100 \mathrm{hr}$ test period. Another fabrication problem associated with screen printing is the limitation on the pattern resolution. The sonicated CNTs within the inks are typically of the order of $5 \mu \mathrm{m}$ in length. These can clog the screen printing mesh resulting in a low porosity and inability to print.

Formation of stabilised, homogenous inks is central to drop, cast, spray, vacuum filtration and screen printing. The formation of these inks, as highlighted above, requires deleterious ultra-sonication and aggressive acid treatments, both of which degrade the length and electronic character of the CNTs. Though the necessary wet chemistry approaches provide a facile, rapid and inexpensive route to fabricate the emitter, the constituent CNTs are coated with deleterious vacuum unstable surfactants that can only be removed following high temperature post-deposition treatments which, if not fully removed, would otherwise cause significant outgassing during FE operation [160]. Maintaining slurry and ink consistency over time and between batches is difficult, which manifests as a reduction in device-todevice reproducibility. It is also challenging to pattern emitters fabricated in this way though screen printing (the migration of CNT inks through patterned apertures within a regular mesh), as demonstrated by Kim et al. Though screen printing is indeed large-area compatible, it is rather low resolution and thus limits the degree of control over the detailed design of the electron source. Oxygen plasma etching coupled to conventional lithographic techniques is another viable option though significant surface roughness of the CNT thin film can again compromise the maximum resolution. Moreover, plasma etching techniques are only applicable to nonorganic substrates.

While there have been reports that electrophoresis can produce a degree of alignment $[179,180]$ this is relative only to very randomly orientated screen printing and ink-based processes. Misalignment prevents any fabricated devices from realising the full field enhancement factor of the composite CNTs; in order to achieve this alternative fabrication methods capable of aligning, en masse, the CNTs must be considered, with chemical vapour deposition being the most promising method to date.

\subsubsection{Chemical vapour deposition}

Chemical vapour deposition (CVD) (Figure 4(f)) provides a more controllable means of growing CNTs. The CNTs self-assemble from atomic units in a highly parallelised process, which when coupled with high resolution lithographic techniques to pattern the catalyst material, allows for near nano-scale engineering of the CNTs and CNFs. CVD techniques mediate the growth of chemically untreated disordered or aligned CNT thin films depending on the substrate, catalyst and growth precursors employed. In a typical implementation, Silicon is coated with a physical vapour deposited metal catalyst which is then patterned via lithographic or masking techniques by either additive or subtractive process, such as magnetron sputtering, or plasma etching, respectively. The substrate is then heated to temperatures often in excess of $500^{\circ} \mathrm{C}$, and the growth of the CNTs on these sites is initiated by supplying a hydrocarbon feedstock gas, such as $\mathrm{CH}_{4}$ or $\mathrm{C}_{2} \mathrm{H}_{2}$, combined with an $a-\mathrm{C}$ etching gas species, typically $\mathrm{H}_{2}$ or $\mathrm{NH}_{3}$ both of which readily pyrolyse to give a constant supply of carbon and atomic hydrogen. In situ plasma can also be employed to enhance the catalysis and align the CNTs during growth. Cole et al. have compiled a concise overview of the CVD of nanocarbons, available elsewhere [181].

Using thermal-CVD synthesised MWCNTs directly deposited on shadow-masked Mo discs (as well as $\mathrm{Si}$, fused quartz, mica, copper, and highly ordered pyrolytic graphite), with a $\mathrm{Al} / \mathrm{Fe}(0.5 / 10 \mathrm{~nm})$ bilayer catalyst, Sarrazin et al. [182] have routinely measured current densities in excess of $1 \mathrm{~A} / \mathrm{cm}^{2}$. Here the MWCNTs were several microns in length and randomly orientated, with most running adjacent to the substrate; CVD techniques allow for CNT alignment, though random orientation is still possible. Very little control over the type, orientation and area packing density of the CNTs was evidenced with a largely qualitative analysis presented. Nevertheless, a turn-on bias of approximately $2 \mathrm{~V} / \mu \mathrm{m}$ was observed. Rather surprisingly, the robustness of the cathodes toward arcing was clearly shown resulting in an increase in the voltage for a given current following repeated arcing events. They suggest that either the emitting sites are not completely destroyed or that they are efficiently replaced by other nanotubes within the film. Indeed, disordered films are structurally dynamic when under the influence of a high electric field, which can augment their emission 
characteristics. Though film reorganisation benefits the long term stability, in that degraded CNTs are in essence replaced, the short term temporal stability is likely to be very poor. More than 100 cathodes were tested and a poor reproducibility was indeed noted, a probable consequence of the disorder and uncontrolled microscale morphology of the emitter.

As is the case for the screen printed and vacuum filtration methods, one potential problem is the degree of adhesion between the CNT and the substrate when exposed to high electric fields. Detailed control of the underlying catalysis has shown that such emitter removal concerns can be solved. Li and Cole et al. showed very low variation in anode current of $< \pm 0.7 \%$ for constant emission over $>200 \mathrm{hrs}$ using an ITO/Ni $(10 / 1 \mathrm{~nm})$ bilayer catalyst which effectively enhanced the degree of adhesion [183].

Using rapid thermal CVD, Kim et al. [184] deposited CNTs directly on stainless steel sheets coated with TiN/ $\mathrm{Ni}$. The emitters showed a maximum current of $2 \mathrm{~mA}$ (data on the emitter area was unavailable) at an anode potential of $5 \mathrm{kV}$. The CNTs were $30 \mu \mathrm{m}$ long, with Raman analysis suggesting a very defective material, whilst scanning electron microscopy showed vertically aligned forests with a high packing density. Though the emission showed good performance the geometry was not optimised; the dense forest results in significant shielding of the CNTs from the applied electric field - the material appears as bulk - such that the full field enhancement factor of the CNTs was not realised in this instance. Whilst individual, one dimensional nanowire and nanotube emitters have been empirically evidenced to produce the highest electric fields, the proximity of other emitters will effectively shield the field enhancement $[146,185]$. In a field emission device, where our interest is in the total available current density, the optimum arrangement will not be that with the highest density of emitters [186,187]. In addition, if the emission pattern of the field emitter is not uniform CVD growth can result in individual CNTs, or structures such as CNT pillar arrays and toroids [160,167,188-191]. Patterns of control electrodes may be grown, in such a way as to focus or concentrate the field from the tip.

The use of CVD to nanoengineer X-ray sources has remained in its infancy due to a number of challenges in explicating the underlying material growth. Nevertheless, following recent advances in the understanding of nanocarbon catalysis [192-194], the use of CVD-grown CNTs and CNFs in FE X-ray sources appears to be accelerating with it emerging as an emerging as an exciting candidate for viable commercialisation.

\subsection{Diode \& triode configurations}

The first examples of X-ray emitters using FE electron sources employed diode configurations which comprised only of a cathode and an anode. However, in such devices the emission current was a function only of the anode voltage. As a result such diode configurations gave rather limited control over the magnitude of the emission current for most applications. To more accurately control the emission current, whilst also providing a degree of protection, it is now standard procedure to introduce a third electrode. This gate electrode gives rise to a triode configuration. Early in the development of CNT-based FE X-ray sources, Sugie et al. [148] introduced a counter-electrode wire. Since this naturally produced an anisotropic beam, the control mechanism of choice became a perforated grid, or gate electrode. The purpose of the gate is to create a local electric field that draws the electrons away from the principal emission beam. However, in practice a significant proportion of the emitted electrons will be attracted towards the gate electrode. The gate must therefore be sufficiently transparent to allow the maximum number of electrons to pass to the anode. It is normal that $>50 \%$ of the cathode current is directed to the gate, thereby limiting the efficiency of such devices. However, there has been recent interesting work on improving the transparency of the gate by incorporating graphene layers. This has shown a substantial improvement in efficiency to around $60 \%$ [195] though the technique has yet to be applied to $\mathrm{X}$-ray sources.

Further, the addition of a fourth electrode, mounted just above the gate, has been described [154]. This electrode had many apertures for each gate perforation, and was mounted approximately $0.2 \mathrm{~mm}$ above the gate electrode. The claimed transmittance of the CNT cathode electrons, to the anode was up to $80 \%$. In addition, there are numerous examples of the addition of a further electrostatic focusing electrodes used to reduce the focal spot size. This is described in more detail below.

\subsection{Demountable tubes}

Many conventional X-ray tubes are constructed using sealed glass or ceramic "inserts". At this stage in the development if FE X-ray sources, many of the published results referenced in this paper relate to tubes constructed in vacuum chambers which can be directly evacuated with turbo molecular, ion, or cryo pumps. Such systems are analogous to the demountable X-ray tube [196]. There are situations where it can be of considerable benefit to have the ability to open a tube, replace damaged components, and re-evacuate it. In particular, this offers the advantage that it is possible to exchange both the anode - either for one of different target characteristics, or to replace a unit which had been degraded as a result of continuous high beam current - and cathode assembly, following failure or deterioration due to prolonged use. To date many CNT 
based sources have been fabricated in what are largely deemed demountable tubes. Clearly, the nature of devices developed for research and design iteration, this is the sensible choice. However some improvements - for example, miniaturisation - have seen the development of a sealed construction $[150,154,197,198]$.

\subsection{Functional enhancements}

Table 1 below summarises the cumulative literature to-date on the progress towards the realisation of a functionally enhanced CNT-based FE X-ray source. Italicised values indicate the highest achieved standards at the time of publication. What follows is a detailed overview and assessment of some of the leading studies with regards to their functional enhancements, fabrication methods, and emission performance.

\subsubsection{Beam profiling}

Many groups have grown CNTs, by CVD or derivatives thereof, directly on conical or other shaped tips, on common Spindt-like materials [213], Si [169,205,214] or bulk metals [200]. As such, these systems do not exploit the full geometric potential of the CNTs; they simply amplify, often only marginally, the existing field enhancement factor of the tip structures and almost always result in an induced asymmetry in the electron beam profile that is challenging to accommodate with conventional electrostatic focussing. Indeed, even conventional $\mathrm{X}$-ray TE cathode assemblies will, in general, produce an anisotropic focal spot, as a result of the electron beam dimensions, imperfect focusing, and the impact of the target angle. One potential route to realising symmetrical X-ray sources with shaped beam profiles is to shape the cathode such that the emergent electron beam defines, at least in part, the spatial distribution of the emergent X-ray beam. This requires patterning of individual CNTs or CNT forests into well-defined geometries. Several groups have considered the use of cathode shaping as a mean to achieve beam profiling. Most have used elliptical cathode geometries to define a circular distribution of the emergent X-ray beam [160]. Two examples are as shown in Figure $5(\mathrm{a}, \mathrm{b})$. Shaping has also been shown to enhance the FE performance by exploiting the natively high field enhancement factor at the shaped emitter's edges. In particular, the group of Milne have shown field emission properties of individual CNFs and patterned forests $[185,215,216]$. No systematic studies on the effect of shaped cathode eccentricity, or other controlled geometrical parameter, on the symmetry or profiling of the emergent X-ray beam appear to have been considered to date. Indeed, the electrophoretically deposited and photolithographically patterned elliptical cathodes of Calderón-Colón et al. [160] showed impressive emission characteristics though no detailed assessment of the emergent beam shape was reported, making is difficult to assess the success of such beam shaping techniques (Figure 5a).

Using Si-supported CNT arrays, Ryu et al. demonstrated the potential of CVD in X-ray source applications [205]. A resist-assisted patterning process was used to produce a cathode assembly consisting of a gate and focusing electrode. This assembly was approximately $0.5 \mathrm{~mm} \times 2.0 \mathrm{~mm}$ and gave an isotropic focal spot [205]. Ryu et al. also described a further shaping technique for post processing the as-grown vertically aligned CNTs. Here they used hydrofluoric acid to produce an array of conical pillars (Figure 5b), rather reminiscent of earlier Spindt emitters. Hydrofluoric acid, though cheap and readily available, is rather hazardous to handle and poses a significant health risk. This somewhat limits the commercial viability of the compaction technique presented. Nevertheless, they demonstrated anode currents of up to $90 \mathrm{~mA}$ at $7.8 \mathrm{~V} / \mu \mathrm{m}$, with a turn-on electric field of approximately $3 \mathrm{~V} / \mu \mathrm{m}$. To increase the geometric uniformity of the emitters the team used an electrical aging treatment, which degrades the taller tubes and bundles that would dominate the emission. For a high performing emitter this aging, also termed seasoning, is not desirable and CNTs of very uniform height and diameter are preferred, as evidenced by Teo et al. [166], to obviate the need for such post-growth treatments. Nevertheless, part of the Ryu et al. ageing process [205] was to remove the Ni catalyst particles at the CNTs apex, which they argued reduced the emission current. Detailed analysis and theoretical studies surmising the emission implications of the metallic nanoparticle in the emitter tip are lacking in the literature.

\subsubsection{High beam current}

High beam current, and therefore current density, is desirable. This gives rise to higher photon flux, and hence shorter detector integration times, in addition to improved signal-to-noise ratios. Combined with the use of gate control to pulse the X-ray source, high beam currents can be very advantageous to system designers. Recently, micro-fabricated Spindt-like emitters have been used for applications such as static tomography [217]. Here each cathode was formed from approximately 50,000 tips covering an area of about $1 \mathrm{~mm}^{2}$. These emitters had a measured current capacity greater than that reported for CNTs, though CNTs will almost certainly exceed this once the technology matures. For current CNT-based sources the emission current density is several orders of magnitude less than that of equivalent area Spindt emitters. Nevertheless, for CNT-based emitters, current densities of up to $1 \mathrm{~A} / \mathrm{cm}^{2}$ have been reported [18], with studies elsewhere suggesting that individual CNTs are capable of conducting current densities 
Table 1 Performance of CNT-based X-ray sources

\begin{tabular}{|c|c|c|c|c|c|c|c|c|c|}
\hline Ref & Year & CNT deposition (substrate) & Max stable beam current $(A)$ & $\begin{array}{l}\text { |Max anode } \\
\text { voltage| (kV) }\end{array}$ & $\begin{array}{l}\text { Pulse } \\
\text { frequency }(\mathrm{Hz})\end{array}$ & $\begin{array}{l}\% \text { drift in anode current } \\
\text { in non-feedback mode }\left(\% \mathrm{l}_{\mathrm{a}}\right)\end{array}$ & $\begin{array}{l}\text { Approx. turn-on } \\
(\mathrm{V} / \mu \mathrm{m})\left(@ J_{\mathrm{a}}\right)\end{array}$ & $\begin{array}{l}\text { Focal spot } \\
\text { size }(\mathrm{mm})\end{array}$ & Notes \\
\hline [159] & 2005 & Electrophoresis & $10 \mathrm{~mA}(15 \mathrm{~V} / \mu \mathrm{m})$ & 40 & DC & $<5 \%$ & $\sim 2.6(/)$ & 0.15 & Micro focus \\
\hline [199] & 2007 & PE-CVD (W and Pd wire) & $50 \mu \mathrm{A} \sim(3 \mathrm{~V} / \mu \mathrm{A})$ & 15 & DC & / & / & 0.05 & Micro focus \\
\hline [163] & 2007 & PE-CVD (W wire) & $26 \mu \mathrm{A}(5 \mathrm{~V} / \mu \mathrm{m})$ & 40 & DC & / & $1.6\left(10 \mathrm{~mA} / \mathrm{cm}^{2}\right)$ & 0.005 & Micro focus \\
\hline [200] & 2010 & PE-CVD (W and Pd wire) & $0.1 \mathrm{~mA}(/)$ & 25 & DC & $<15 \%$ & $3.2(/)$ & 0.0004 & Micro focus \\
\hline [201] & 2004 & Solution Processed & $6 \mathrm{~mA}(15 \mathrm{~V} / \mu \mathrm{m})$ & 60 & $10^{7-8}$ & $< \pm 1 \%$ & $\sim 7.1(/)$ & $0.15 \times 0.03$ & $\begin{array}{l}\text { Micro focus high } \\
\text { pulse rate }\end{array}$ \\
\hline [149] & 2002 & Electrophoresis & $28 \mathrm{~mA}(/)$ & 14 & $10^{3}$ & $\pm 2-4 \%$ & $2.0\left(1 \mathrm{~mA} / \mathrm{cm}^{2}\right)$ & 3.2 & Pulsed \\
\hline [202] & 2006 & / & $1 \mathrm{~mA}()$ & 40 & 1 & $\sim 50 \%$ & / & 0.2 & Pulsed multi-pixel \\
\hline [203] & 2009 & Electrophoretic & $18 \mathrm{~mA}$ & 30 & $10^{2}$ & / & $\sim 5.0(/)$ & $0.5 \times 0.3$ & $\begin{array}{l}\text { Pulsed multi-pixel } \\
(25 \times 1)\end{array}$ \\
\hline [171] & 2011 & Screen Printing & $43 \mathrm{~mA}(/)$ & 45 & 5 & $\pm 0.2 \%$ & / & 0.6 & $\begin{array}{l}\text { Pulsed multi-pixel } \\
(31 \times 1)\end{array}$ \\
\hline [203] & 2009 & Electrophoresis & $18 \mathrm{~mA}(/)$ & 40 & $10^{3}$ & $<7 \%$ & $6.5(/)$ & 0.1 & $\begin{array}{l}\text { Multi-pixel }(25 \times 1) \\
\text { shaped cathode }\end{array}$ \\
\hline [169] & 2011 & Electrophoresis & $3.5 \mathrm{~mA}(7.5 \mathrm{~V} / \mu \mathrm{m})$ & 1.4 & DC & / & $3.5\left(10 \mu \mathrm{A} / \mathrm{cm}^{2}\right)$ & 2.0 & Multi-pixel $(5 \times 10)$ \\
\hline [204] & 2013 & CVD & $0.6 \mathrm{~mA}(16 \mathrm{~V} / \mu \mathrm{m})$ & 40 & DC & / & $\sim 8(/)$ & / & Ballasted \\
\hline [160] & 2009 & Electrophoresis & $7.0 \mathrm{~mA}(8.5 \mathrm{~V} / \mu \mathrm{m})$ & 50 & 10 & $\pm 13 \%$ & $5(/)$ & 0.1 & Shaped cathode \\
\hline [205] & 2012 & CVD & $90 \mathrm{~mA}(7.5 \mathrm{~V} / \mu \mathrm{m})$ & 50 & DC & / & $3.0(0.1 \mathrm{~mA})$ & / & Shaped cathode \\
\hline [206] & 2006 & DC Electrophoresis & $150 \mathrm{~mA}(12 \mathrm{~V} / \mu \mathrm{m})$ & 40 & $10^{2}$ & / & / & 0.03 & $\begin{array}{l}\text { Shaped cathode } \\
\text { pulsed micro focus }\end{array}$ \\
\hline [182] & 2004 & CVD (Mo disk) & ca. $15 \mathrm{~mA}(4.6 \mathrm{~V} / \mu \mathrm{m})$ & 1.1 & $10^{-1}$ & / & $\sim 2.0(/)$ & 0.5 & $\begin{array}{l}\text { Miniature battery } \\
\text { operated }\end{array}$ \\
\hline [150] & 2004 & CVD & $0.3 \mathrm{~mA}(7.0 \mathrm{~V} / \mu \mathrm{m})$ & 30 & DC & $\pm 8 \%$ & / & / & Miniature \\
\hline [198] & 2005 & / & $\sim 40 \mu \mathrm{A}(/)$ & / & $2 \times 10^{3}$ & $\sim 50 \%$ & / & 1.0 & Miniature \\
\hline [207] & 2012 & Paste & $0.6 \mathrm{~mA}(1.4 \mathrm{~V} / \mu \mathrm{m})$ & 70 & DC & $\pm 2 \%$ & / & 3.7 & Miniature \\
\hline [208] & 2013 & Paste & $1.2 \mathrm{~mA}(4.7 \mathrm{~V} / \mu \mathrm{m})$ & 25 & 10 & $\sim<1 \%$ & $\sim 3.5(/)$ & / & Miniature \\
\hline [209] & 2004 & CVD (Mo disk) & $\sim 2 \mathrm{~mA}(4.65 \mathrm{~V} / \mu \mathrm{m})$ & 10 & $10^{-1}$ & / & $2.2(10 \mathrm{nA})$ & 0.5 & Miniature pulsed \\
\hline [210] & 2006 & Ion bombardment (polyimide) & / & 25 & $6 \times 10^{2}$ & / & $1.5\left(1 \mu \mathrm{A} / \mathrm{cm}^{2}\right)$ & / & / \\
\hline [148] & 2001 & CVD (metal wire) & $1.5 \mu \mathrm{A}(20 \mathrm{~V} / \mu \mathrm{m})$ & 60 & DC & $\pm 10 \%$ & / & / & / \\
\hline [151] & 2004 & PE-CVD (W and Pd wire) & $1 \mathrm{~mA}(/)$ & 40 & DC & $\pm 8 \%$ & I & 2.0 & / \\
\hline [184] & 2007 & CVD & $2.0 \mathrm{~mA}(0.5 \mathrm{~V} / \mu \mathrm{m})$ & 10 & DC & $\sim 50 \%$ & $\sim 0.2(/)$ & / & / \\
\hline [211] & 2008 & PE-CVD (Pd wire) & $1.0 \mathrm{~mA}(/)$ & 50 & DC & $\pm 10 \%$ & / & 3.0 & / \\
\hline$[154,212]$ & 2014 & Screen Printing & $15 \mathrm{~mA}(2.6 \mathrm{~V} / \mu \mathrm{m})$ & 20 & 10 & / & / & 0.3 & / \\
\hline
\end{tabular}



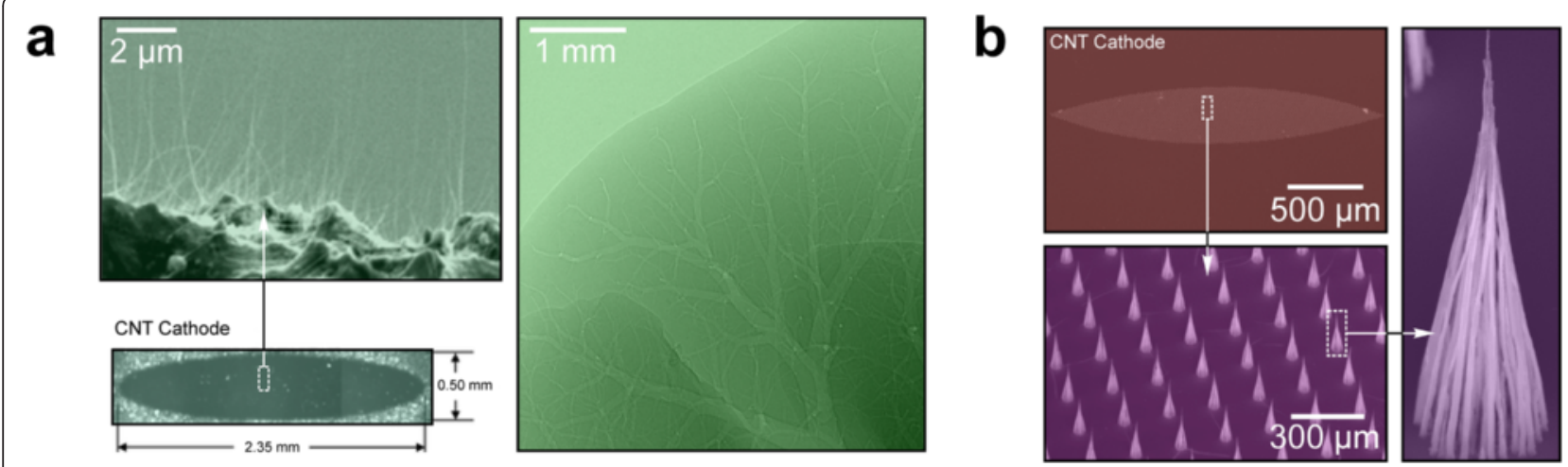

Figure 5 Shaped CNT cathodes. Control over the electron beam distribution, and subsequent symmetry of the X-ray beam, can be achieved by shaping the electron emitting areas on the cathode by conventional lithographic techniques. (a) A screen printed elliptical shaped electron emitter and subsequent X-ray image of a leaf [160] (Scale bars: $2 \mu \mathrm{m}, 1 \mathrm{~mm}$ ). Copyright Institute of Physics. (b) Scanning electron micrographs of

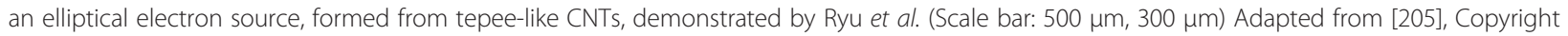
2012, Multidisciplinary Digital Publishing Institute.

corresponding to $5 \times 10^{6} \mathrm{~A} / \mathrm{cm}^{2}$ [218], which is significantly larger than any attained by Spindt-like emitters fabricated to date.

Using electrophoretically deposited SWCNTs [167], high electron beam currents have been achieved using a triode configuration by Yue et al. [149]. Here, the gate assembly was mounted approximately $100 \mu \mathrm{m}$ adjacent to the CNT electron emitter resulting in a device geometry capable of sustaining a beam current of several milliamps, although this would likely prove challenging to manufacture in a practical X-ray source. In addition, they demonstrated peak pulse currents of up to $28 \mathrm{~mA}$ (emitted area not stipulated), without vacuum breakdown, at an anode potential of $14 \mathrm{kV}$. Using CVD grown CNT arrays, Ryu et al. [205] reported emission currents of up to $90 \mathrm{~mA}$ (emitted area not stipulated) in a diode configuration, although in a gate-controlled triode arrangement, the beam currents were substantially reduced.

Some improvement towards increasing the current density has also been achieved by controlling the emitter morphology. Toroidal CNT arrays, which have a central void [191], are one such example. By subsequent surface treatments, it is also possible to enhance the native $\mathrm{FE}$ characteristics of such arrays by means of the formation of nano tips, tepees and micro cones, as outlined previously $[190,205]$. The use of emitter forming post-treatments has also been widely investigated. One leading example is the use of conical CNTs which enhanced the beam current and stabilised the emitter geometry. Another alternative towards higher beam currents is to augment the electronic character of the CNTs, via the dry or wet deposition of various adlayers. Such adlayers adjust the interfacial characteristics at the critical emitter-vacuum interface. This often leads to a decrease in the turn-on voltage and increase the emission current density at a given anode bias. As was highlighted above, FE is highly surface sensitive; at
$10^{7} \mathrm{~A} / \mathrm{cm}^{2}$ a $1 \%$ change in the surface work function, due to intentional adlayer sputtering or indirect sputtering from reactive gas species in the vacuum cavity, can increase the current density by more than $10 \%$ [152]. Little work has been reported on the use of adlayers to enhance the emission performance of CNT-based FE X-ray sources. Nevertheless, significant advantages may be achieved by carefully designing the emitter-vacuum interface to provide high emission currents, limit adverse effects of vacuum leakage, prevent unintentional work function shifts, as well as robustness towards local ionisation and plasma etching, all of which are critical in ensuring long term stability.

\subsubsection{Enhanced temporal stability}

The failure mechanisms of Spindt and CNT based emitters, which are similar in many respects, have been widely studied [219], most notably by Bonard et al. [220]. Thermal migration, field sharpening and subsequent avalanche breakdown are perhaps the most common failure mechanism in such whisker-like emission geometries [221]. Although recent work on CNT-based emitters has shown impressive lifetimes of 7000 hours, with only a $10 \%$ emission degradation [222], it remains an on-going challenge to design and fabricate high temporally stable emitters. As noted previously, the electron emission is sensitive to the bulk emitting material and the emitters' surface chemistry. CNTs have a high sublimation temperature and high maximum current densities, making them resilient towards arcing events. Pristine CNTs are also largely inert, although when defects are added to the graphitic lattice, often through plasma processing, they are readily damaged and the formed dangling bonds bolster the CNTs emission performance, though often at the expense of the long term stability. The enhanced emission is due to the augmented surface characteristics. This effect is often 
noted as a shift to higher turn-on bias during hysteresis studies. Indeed, many plasma and some dopants, such as oxygen when the emitter outgases, can be particularly damaging to the CNTs. Local Ohmic $\left(\mathrm{I}^{2} \mathrm{R}\right)$ heating can also increase the rate of emitter degradation, as can vacuum breakdown. It has been shown that the axial resistance of CNFs increases with increasing temperature. Interestingly this intrinsic property helps protect the CNFs from degradation during local heating and helps prevent thermal run-away deleteriously increasing the emission current [221]. Vacuum breakdown results in the emission of extremely high current densities which may cause a plausible local oxygen micro-plasma formation - this etches the CNTs, particularly at their apex. This shaping stimulates the formation of defects in the graphitic lattice, which preferentially emit electrons, thereby enhancing the emission, however; this results in a temporally unstable emission profile. The CNTs can be sharpened with time, which tends to increase the emission current, or can alternatively be entirely ablated, which reduces the emission current due to the reduced number of electron emitters available.

There have been various methodologies proposed which attempt to reduce temporal instabilities. Thermal annealing or electrostatic seasoning, to remove residual surfactants and non-uniform emitter profiles, are perhaps the most common and certainly the most simple and readily implemented [160]. During thermal annealing the cathode assemblies are heated to temperatures in excess of $300^{\circ} \mathrm{C}$ under high vacuum conditions. This out-gases the emitter, removing weakly surface bound chemisobed species. This increases the work function uniformity across the surface of the emitter. Such outgassing techniques are also useful in emitter recovery following an arcing event. Arcing events stimulate high current flow which heats and subsequently out-gases the emitter. This out-gassing can lead to further transient arcs which, if allowed to continue, will degrade the emitter. If the emitter is initially well out-gassed any local arcs will only marginally increase the cavity pressure and the emitter will stabilise more rapidly. Annealing is also employed to enhance the pressure of the vacuum cavity, making local plasma formation increasingly unlikely. In the case of electrostatic seasoning, the extraction electric field is slowly ramped up to around $80 \%$ of the nominal emission voltage. The emitters are then left emitting for tens to hundreds of hours to increase the surface smoothness of the emitter and hence, stabilise the emission current. Such approaches are critical in achieving intrinsic emitter stability, and though feedback techniques have been employed to artificially control the stability, engineering intrinsic stability remains central to the formation of a long-term stable emitter. In feedback based systems, in the same way as conventional TE generator designs, the anode current is monitored and the extraction voltage adjusted accordingly to maintain a known, safe, emission current. Though a viable and widely adopted approach to ensuring emitter stability, the slow response times of the feedback loop cannot entirely remove transient effects, such as arcing events, and only careful design of the electron source can facilitate this.

Though CVD is certainly coming to the fore as the most reproducible fabrication technique with the finest degree of control over the emitter design, it, like other techniques, is faced with issues of tip-to-tip uniformity. Poor uniformity in effective surface roughness is known to de-stabilise the temporal stability. Indeed, wet chemistry ink approaches to emitter fabrication result in much greater surface roughness, and this exacerbates and further compromises their temporal stability. Small height variations between tips can instigate preferential emission from a small proportion of the longer CNTs, which consequently burn-out. It has been shown elsewhere that individual CNTs can in practice pass a current of several microamps [223]. Currents in excess of this threshold cause the CNT to sublime, which manifests as a temporal instability in the anode current, and subsequent X-ray emission. In the case of CVDsynthesised CNT emitters one solution - originally described for application with Spindt emitters [224] and initially proposed for general electron emission applications by [183] - consisted of integrating a ballast resistor micro-fabricated in series with the electron emitter. Here resistive deposited layers are fabricated in series with the electron emitters. The series resistance ballasts the emission, functioning as a current limiting resistance, preventing emitter sublimation, subsequently enhancing temporal stability. Yet to be applied immediately to the design of an X-ray source, the group of Milne have developed a novel field effect transistor (FET) ballasted field emission source, where each individual CNF electron source is equipped with its own dedicated FET ballast layer which is capable of limiting, and electronically controlling, the emission current to prevent emitter sublimation and significant temporal instabilities [183]. Other thin film deposition techniques have also been considered [204,225] though these too have yet to gain any significant interest.

Individual CNTs are fragile. Their propensity toward tip or root growth results in an axial asymmetry in their magnetic susceptibility which manifests as rotational torque induction when exposed to high electric fields an effect which is typically exploited during electrophoretic alignment. However, during FE this can result in the removal and transfer of the CNTs from the cathode to the anode. This severely impacts the lifetime and stability of any field emission device into which they are 
incorporated. Several approaches have been taken to improve the robustness of the emitting elements by increasing the degree of adhesion between the CNTs and the supporting substrate. Bundles of vertically aligned CNTs - typically with a height of around $10 \mu \mathrm{m}$ or less, and a diameter of $30 \mu \mathrm{m}$, have been shown to be one such robust assembly, that is not readily damaged or easily removed. However, FE preferentially occurs at the periphery of the patterned CNT forest or array $[188,189]$ suggesting that if some CNTs are in fact removed the emission stability may simply be recovered by new CNTs contributing the emission current of those removed; emitter areal design can in part accommodate and engineer out temporal instabilities. Nevertheless, there is a continuing effort to engineer the CNT-support interface to enhance the degree of adhesion and hence enhance the temporal stability. In the case of ink approaches various solution additives have been exploited, such as glass frits [160], though the exact implications of such approaches with regards to the turn-on field and maximum current density remain unclear.

Elsewhere there has been significant work on the use of surface treatments to stabilise the temporal stability of the electron emission [205,226]. As discussed previously, such low work function adlayers do indeed increase the emission current density, though they also, depending on the adlayer material and means of deposition, hermetically seal the CNTs - which act as a high aspect support structure - thereby increasing the emitters stability [225].

\subsubsection{Micro focal sources}

FE sources have the potential for extremely high spatial modulation. By controlling, the electron emitter location at the nanoscale, coarse control over the position of the electron beam, and subsequent X-ray beam are possible. A range of focussing techniques has also been developed to reduce the electron beam focal spot size. Standard Xray tubes have a focal spot size of typically around $1 \mathrm{~mm}$ diameter. For greater spatial resolution, "mini-focus" Xray tubes have been developed, with a spot size down to $50 \mu \mathrm{m}$, as well as "micro focus" X-ray tubes with a spot size of $\sim 5 \mu \mathrm{m}$ [227]. Almost exclusively, X-ray sources with effective focal spot sizes of $<10 \mu \mathrm{m}$, which are commercially available, employ electrostatic or magnetic focussing and require high beam current pulsing techniques, to prevent limitation in their imaging resolution by motioninduced blurring [206]. The size of the electron beam at its source and latterly as it impacts the target material, contributes, in part, to the size of the X-ray focal spot, which itself impacts on the resolution of the resultant X-ray image. A large electron beam focal spot will create a penumbra effect where the X-ray spot subtends a significant angle at the subject; this blurs the resultant image.
Conventional X-ray tubes will use a lensing cup around the heated filament assembly. This, to a first order, electrostatically focuses the electrons onto the centre of the anode. Careful design of the cathode and supporting electrostatic lenses will minimise the size of the focal spot $[228,229]$. Additionally, further electrostatic rings or focussing coils may also be employed to redirect the flow of electrons emanating from the cathode, to further reduce the spot size, where the focal spot size is determined by measuring the Point Spread Function using standard methods [230].

In just such a way, a transmission CNT X-ray tube with a solenoid focussing unit was constructed by Heo et al. to produce a $5 \mu \mathrm{m}$ focal spot [163]. Liu et al. developed a single electrostatic focusing lens to produce a source with a nominal focal spot size of $65 \mu \mathrm{m}$, which was further reduced to $35 \mu \mathrm{m}$ by limiting the dimension of the cathode assembly [231], a concept yet to be fully exploited. A similar mini-focus tube, used for small animal CT work, was also described. This used two focussing electrodes to produce a focal spot size of about $100 \mu \mathrm{m}$, using a mesh gate electrode to maximise the electron emission from the cathode [232]. FE tubes with cathodes constructed from CNFs have also incorporated conventional three stage electrostatic Einzel lenses. Such systems have achieved focal spot sizes down to $40 \mu \mathrm{m}$ [200].

\subsubsection{Pulsed sources}

FE sources have the potential for unprecedented temporal modulation. Compared to other one-dimensional nanomaterials, CNTs allow for near ballistic conduction making them ideally suited for such high-speed applications. Pulse X-ray sources are practically beneficial when imaging moving objects. The principle of operation is analogous to stroboscopic lighting in optical imaging. Conventional TE X-ray sources are generally not capable of rapid control; they cannot be pulsed much more rapidly than a few tens of milliseconds, without sophisticated gating mechanisms. The means of controlling the beam current in a TE source is by adjusting the filament current and hence temperature, which introduces time delays due to the finite cooling and heating time of the filament. Pulse sources are therefore generally implemented by switching the anode voltage, or by means of mechanically controlled shutters, the latter only allowing for relatively course control over the pulse shape, on period, and mark-to-space ratio, and will inevitably create a trapezoidal pulse. In the case of existing FE and TE sources, the short duration of the pulse must be compensated by increased power levels, resulting in significant engineering design constraints with regards to the resilience of the emitting material; conventional electron emitting materials degrade rapidly when used in such high power applications. 
In FE X-ray sources often the means of controlling the beam current is via the gate voltage. Depending on the exact emitter geometry, this voltage can be considerably lower than the anode voltage and so at a much lower power level; it can be switched virtually instantaneously. Gate electrodes can certainly be incorporated into more traditional TE sources also, though much more control over the on/off current ratio and pulsing performance can be achieved when using FE sources as the gate and anode can be controlled simultaneously, with both responding rapidly. The result is a FE X-ray source that may readily be pulsed with a high on/off current ratio. This lowers the total thermal dissipation, reduces the total amount of emitted radiation - allowing for safer medical diagnostics, and eliminates the need for bulky mechanical components.

Most devices fabricated to date operate in either DC or low frequency (tens of $\mathrm{Hz}$ ) mode [148,150,151,154,160, $163,169,171,182,184,159,200,202,204,205,207-209,211,212]$ with only a very limited set of electronically controlled devices operating at frequencies in excess of a few hundred $\mathrm{Hz}$ to a few $\mathrm{kHz}[149,198,203,210]$. The highest electronic pulse rate achieved to date is of the order of $10^{7} \mathrm{~Hz}$, as reported by Cheng et al. [201]. Nevertheless, the pulse rate achieved by Thales [233] in their optically gated devices exceeds all other devices by a significant margin. Figure 6(a) shows the anode current and X-ray intensity temporal response by Reyes-Mena et al. [198]. Here the X-ray beam $0-90 \%$ turn-on time is $<50 \mu \mathrm{s}$ and the system is used to image a rotating cooling fan. Images were acquired at a constant fan angular velocity with decreasing X-ray emission pulse width. As the X-ray pulse width decreases the fan blade sharpness increases evidencing the usefulness of beam pulsing in acquiring high resolution images in moving systems. The pulsing of the gate voltage has also been shown to produce turn on times of the order of $100 \mu \mathrm{s}$ $[149,198]$. At an early stage, Yue et al. [149], as shown in

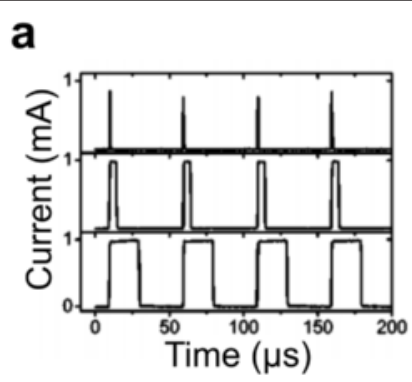

b

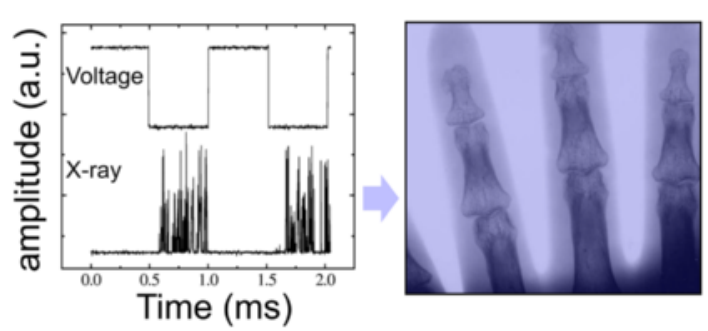

d

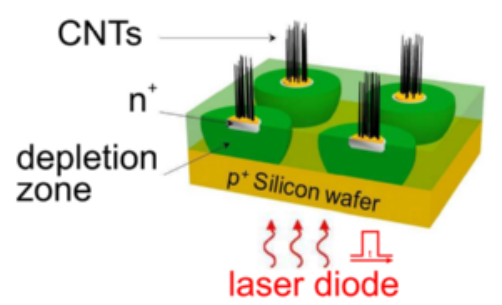

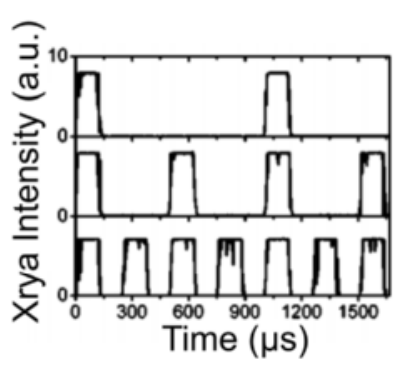

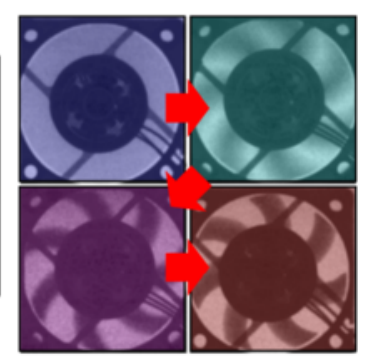

C
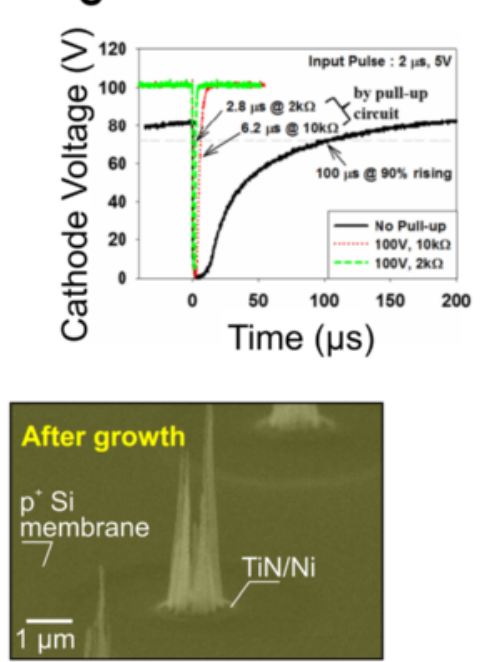

Figure 6 Pulsed Sources. (a) Anode current and X-ray intensity temporal response plots showing an X-ray beam turn-on time of $<50 \mu$, and $X$-ray images of a rotating computer cooling fan acquired at a constant fan angular velocity with decreasing X-ray emission pulse width. Note the increased sharpness of the fan blades with increasingly rapid beam pulsing [198]. Copyright 2005, Joint Committee on Powder Diffraction Standards. (b) Bias voltage and X-ray emission temporal response plots with an acquired X-ray image of a users hand [149,156]. Copyright 2003, Elsevier and American Institute of Physics. (c) The time dependence of the cathode voltage with integrated pull-up resistance showing a rise time of <3 $\mu$ s [154]. Copyright 2013, SPIE. (d) Schematic depiction of a red-source photo-gated CNF-based electron source. Each vertically aligned CNF bundle sits on top of a pin $^{+}$photodiode coated with a TiN diffusion barrier coated and a Ni catalyst, as illustrated in the scanning electron micrograph taken after the CNT growth (Scale bar: 1 mm). Adapted from [233]. Copyright 2014, Thales Electron Devices. 
Figure 6(b), demonstrated peak beam currents of up to $28 \mathrm{~mA}$, at anode potentials of $14 \mathrm{kV}$, without degradation of the field emitters. An interesting artefact of their rapid pulsing was the chaotic and rather noisy X-ray emission, which showed an approximate periodicity of $100 \mu \mathrm{S}$. The noise here must certainly be reduced if a practical device is to be realised.

The limiting factor in many pulsed systems is often the capacitance of the gate assembly. Kim et al. [154] showed that pulsing performance could be improved and demonstrated $<3 \mu$ s pulse periods, as indicated by the cathode voltage, via the use of a simple high voltage MOSFET pull-up circuit to switch the cathode, proposing that their pulsed source may find application in angiography. However it is worth noting that such a measure does not correlate with the X-ray photon flux [198]. Liu et al. [206], by pulsing the gate bias using a pulse generator with a constant anode bias of $40 \mathrm{kV}$, showed a stable $0.3 \mathrm{~mA}$ temporal response over $15 \mathrm{~h}$ with an approximate pulse rise time of $<5 \mathrm{~ms}$. Certainly electronic control over the pulsing performance has some use. Though the bandwidth is dramatically reduced, by at least an order of magnitude, the on/off ratio can be increased and the emitter fabrication simplified. Nevertheless, this is necessarily at the expense of other technological challenges, chiefly the associated $\mathrm{RC}$ constant of the vacuum cavity. This $\mathrm{RC}$ constant induces intrinsic time delays that are not experienced in the optically stimulated case. As illustrated in Figure 6(c), Kim et al. [154] employed $10 \mathrm{k} \Omega$ pull-up resistances to negate $\mathrm{RC}$ lag issues. The pulsing performance of arrayed sources has also been considered. Wang et al. [169] showed millisecond temporal response in a matrix source designed for micro radiotherapy. This had an array of $5 \times 10$ pixels achieving an emission current of $3 \mathrm{~mA}$ per pixel.

In order to obviate issues associated with the devices RC time constants, as depicted in Figure 6(d), Thales Electron Devices exploited integrated photodiodes and direct optical excitation. Vertically aligned CNFs were grown on $\mathrm{p}-\mathrm{i}-\mathrm{n}^{+}$photodiodes on a back etched $\mathrm{Si}$ membrane. The $\mathrm{n}+$ doped areas were defined by ion implantation in a $5 \mu \mathrm{m}$ thick intrinsic layer, whilst the $\mathrm{p}+$ doped silicon wafer was subsequently thinned to obtain the $7 \mu \mathrm{m}$ thick membrane [233]. These arrayed emitters where then irradiated, over the entire emitter area, with pulsed red laser light allowing them to attain very high bandwidth and on-off ratio of around 10 , in addition to a maximum on current density of around $100 \mu \mathrm{A} / \mathrm{cm}^{2}$.

The availability of rapidly pulsed sources opens up the potential for high-speed, real-time inspection technologies, capable of coupling high throughput, on-line manufacturing with real-time inspection. Indeed, with controlled high pulse rates the potential to perform medical diagnostics without strict patient restraints is accessed, allowing inspection of dynamic organs without image blurring. Intrinsic motion and the associated quasi-periodic respiration and heart beats, for example, allow one means of gating such high speed pulsed systems. One possible approach considered is to lock the gate electrode pulsing to the patients' cardiac or respiration signal. Such motion-induced artefacts can thus be reduced as the X-ray exposure is synchronised with a patients physiological rhythm, or indeed an objects motion [206].

\subsubsection{Static tomography \& tomosynthesis}

$\mathrm{X}$-ray based Computed Tomography (CT) imaging is fundamental to medical diagnostics. However, at present such imaging devices are affected by long scan times. Enabled by advances in computer and detection technologies, integration time issues are exacerbated when considered in relation to the concept of real-time 3D Xray imaging. Multi-pixel sources offer one viable solution. Multi-pixel sources present a unique opportunity in nextgeneration inspection techniques, especially when one considers the physically small CNT FE cathodes, and the potential for nanoengineering and rapid switching. Pulsed multi-pixel sources give rise to a series of previously challenging applications typically relating to real-time medical diagnostics [234]. Tomography relies on the acquisition of large numbers of images, whilst viewing a subject at a range of angles. These systems, at present, incorporate multiple sources which are sequentially switched. This allows the system to capture an array of independent images without the necessity to physically rotate components, patients, or samples on an expensive and bulky gantry. The emerging alternative is to have multiple, distributed X-ray sources. Here, the subject remains stationary with the added benefit of more rapid data acquisition and potentially higher image quality. Indeed, such systems are largely immune to image blurring, which persists in conventional moving-source systems.

A range of different approaches to the application of tomography or tomosynthesis have been presented. The University of North Carolina, as illustrated in Figure 7(a), have demonstrated high-resolution stationary tomosynthesis using 31 individually addressed CNT X-ray sources distributed within a single large vacuum enclosure [234]. Each source had a $0.6 \mathrm{~mm}$ focal spot size, was operated at $28 \mathrm{kV}$ at an anode current of $38 \mathrm{~mA}$. Though an excellent demonstrator of the potential of CNT-based multi-pixel sources, the system is extremely large and fails to fully exploit the potential of emerging CVD techniques to pattern multiple sources on a single chip as a means to facilitate miniaturisation. Nevertheless, the system is at present one of the most advanced CNT-based FE X-ray sources available. It is based on physically separate CNT ink deposited thin films with 

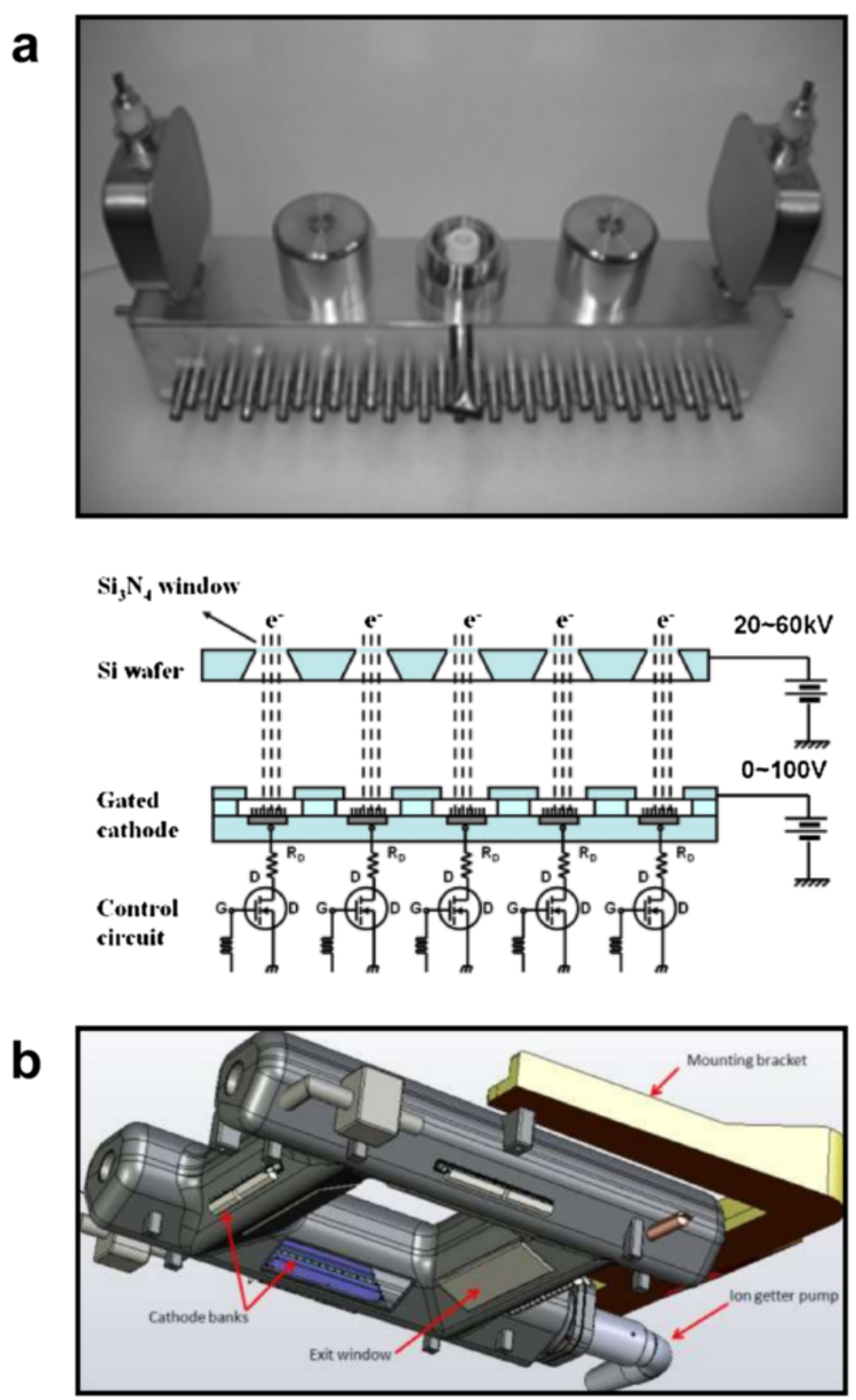

Figure 7 CNT-based tomosynthesis systems. (a) A distributed CNT tomosynthesis unit consisting of 31 individually addressable X-ray sources enclosed in a single vacuum chamber, and below a schematic the corresponding drive circuitry. Adapted from [234]. Copyright 2012, American Association of Physicists in Medicine. (b) An actively pumped multi-pixel X-ray source consisting of 52 individually controlled sources. Courtesy of the University of North Carolina at Chapel Hill [235].

inter-emitter pitches of the order of a few tens of centimetres. The system has also, rather impressively, demonstrated real-time 3D image reconstruction. Figure 7(b) shows another stationary computed tomography system by the same team. This system consists of 4 cathode banks, with a total of 52 separate cathode assemblies. Though rather large and limited to stationary or slow moving objects, this prototype system is the first in a new wave of CNTbased real-time 3D tomosynthesis scanners.
High spatial resolution requires a small X-ray spot size. However, practical systems also require a wide field of view in order to be able to inspect suitably large areas. Thus, to realise high resolution large area scans the Xray source must be constructed from multiple cathodes, each with dedicated focusing electrodes. One way to maximise the field of view is to carefully engineer the vacuum chamber to maximise the total angular field of view. A 5 pixel source system has been constructed by 
Zhang et al. [236]. This system provided sequentially acquired images over a finite angular range, each fitted with an electrostatic focusing electrode to control the size and scanning of the focal spot, which had a width of less than $300 \mu \mathrm{m}$. Operating at $40 \mathrm{kV}$, they showed that the electronic switching time was largely negligible with high emission reproducibility, both in FE curves and beam diameter, between the individual electron sources. Yang et al. demonstrated a multiple source digital breast tomosynthesis unit using an array of 25 cathodes, each individually programmed using analogue controls. Their sources employed CNT-based inks, each with a dedicated gate and an electrostatic focusing ring to control the focal spot size to approximately $200 \mu \mathrm{m}$ [237]. In this system an impressive total angular field of view of up to $48^{\circ}$ was realised, and the performance compared favourably with commercially available moving-source systems. A similar system, termed a multi-beam FE Xray source, described a similar geometry [203]. A simple linear multiple source using an array of 31 CNT FE cathodes has also been constructed, for the purposes to digital breast tomosynthesis, which was shown to be capable of a total scan angle of $30^{\circ}$ [171]. In a further extension, a digital chest tomosynthesis scanner was demonstrated [238]. This system used 75 CNT FE sources, operating at up to $80 \mathrm{kV}$ with a $20^{\circ}$ beam angle.

\subsubsection{Multi-pixel sources}

In the majority of the multi-pixel systems discussed the electron sources have largely been constructed using individual cathodes fabricated in linear arrays. A two dimensional geometry based on a series of linear arrays in a square or hexagonal format of physically separate detectors and sources, has been evaluated using simulation. Such a system is highly manufacturable [239], however; the inspection technique relies on close alignment of the generators and detectors which is likely challenging. Guzilov et al. [240] proposed circular arrays of FE emitters to emulate the classical rotary gantries used for $\mathrm{CT}$, although their practical implementation has been limited to staggered linear arrays. Two dimensional arrays have a number of advantages over their linear counterparts, chief amongst which is the potential for ad hoc beam shaping of the emergent X-rays. Microintegration of two dimensional source arrays allows for ever higher spatial resolution and subsequent beam shaping. Such micro-integrated two dimensional FE source arrays have been realised, though only few such devices have been investigated. Figure 8 (a) depicts a $5 \times$ 10 electron beam array fabricated by Wang et al. [169], as mentioned above. Deposited using inking techniques (Figure $8(\mathrm{~b})$ ), the 50 individually addressable electron beams allow for arbitrarily defined, and controllable electron, and hence X-ray beam shapes, for application in radiotherapy. An example of one such ad hoc beam shaped, electronically defined, X-ray intensity distribution is illustrated in the bottom image of Figure 8(c). A dose rate of $1.24 \mathrm{~Gy} / \mathrm{min}$ at the centre of the irradiated object was obtained at an emission current of $3.0 \mathrm{~mA}$ [169]. High energy sources for tomosynthesis based on such multipixel sources, with high anode potentials of up to $160 \mathrm{kV}$, have also been demonstrated by Sprenger et al. [241]. This was achieved using a square array of $4 \times 13$ electron sources for applications including image guided radiotherapy.

\subsubsection{Compact \& miniature sealed tubes}

$\mathrm{X}$-ray generators are often bulky devices, as a result of the thermal disspiation and subsequent cooling requirements. Certain user specifications necessitate significant miniaturisation. Miniaturised sources find use in handheld non-destructive testing, X-ray spectroscopy, electrically controlled brachytherapy and in situ radiation therapy. Miniature TE sources have been available for many years, but have proven challenging to miniaturise [242]. Amptek has launched a series of miniature X-ray sources [243]. Sealed FE sources, on the other hand, lend themselves to these applications, and in particular are well suited for portable X-ray applications. Though difficult to manufacture, miniaturised sources are emerging on the market place. As in the case of pulsed and multi-
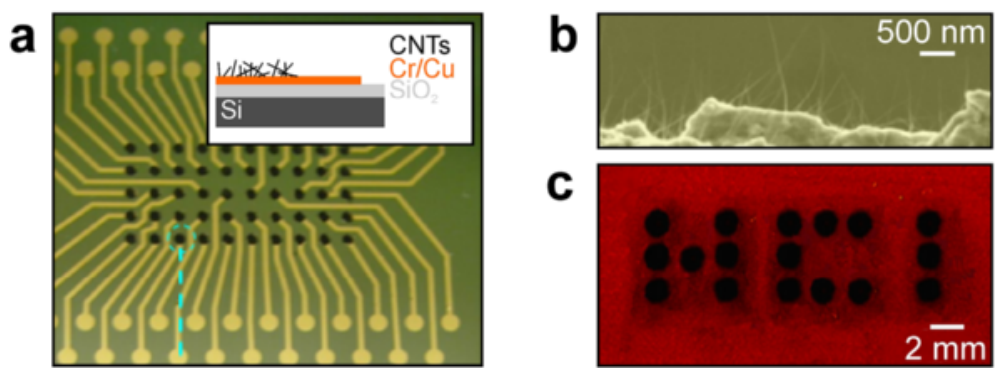

Figure 8 Multi Pixel Sources. (a) Electrophorectically deposited multiple X-ray source chip and the corresponding (b) scanning electron micrograph of deposited CNTs, and (c) he resulting electronically reconfigurable X-ray distribution. Adapted from [169]. Copyright 2011, American Institute of Physics. 
pixel sources, much progress has been made towards a miniaturised CNT-based FE X-ray source though, to the best of the authors' knowledge, no such devices have, as yet, made it to market.

One of the smallest tubes fabricated, at the time of publication, as far as the authors' are aware, is that of the Electronics and Telecommunications Research Institute, Korea (Figure 9(a)). This cylindrical diode source, which is smaller than the average human finger, has an impressive outer diameter of only $6 \mathrm{~mm}$ and a length of $31 \mathrm{~mm}$, and is based on CNTs deposited by a paste printing technique [208,244]. Developed for miniaturised $\mathrm{X}$-ray diffractometry, the X-ray source of Sarrazin et al. [182], Figure 9(b), can support current densities of up to
$1 \mathrm{~A} / \mathrm{cm}^{2}$, whilst Heo et al. [207], who demonstrated a $10 \mathrm{~mm}$ diameter and $50 \mathrm{~mm}$ long miniature source, as illustrated in Figure 9(c), derived around $0.12 \mathrm{~A} / \mathrm{cm}^{2}$. The sealed device can be operated up to $70 \mathrm{kV}$. The cathode was formed from sintered SWCNTs mixed with Ag nanoparticles to form a paste which was deposited on a flattened, $0.8 \mathrm{~mm}$ diameter, $\mathrm{W}$ wire. Here a conically machined Be window was magnetron sputtered with a $1.5 \mu \mathrm{m} \mathrm{W}$ thin film forming a transmission type X-ray target. The vacuum brazed alumina tube with Kovar electrodes and non-evaporable getters weighs just $14.5 \mathrm{~g}$. The bias required to extract $10 \mathrm{~mA} / \mathrm{cm}^{2}$ was $29 \mathrm{kV}$, with a maximum current density of $0.12 \mathrm{~A} / \mathrm{cm}^{2}$, giving a nominal stability of $\pm 2 \%$ at $50 \mathrm{kV}$, with a similar
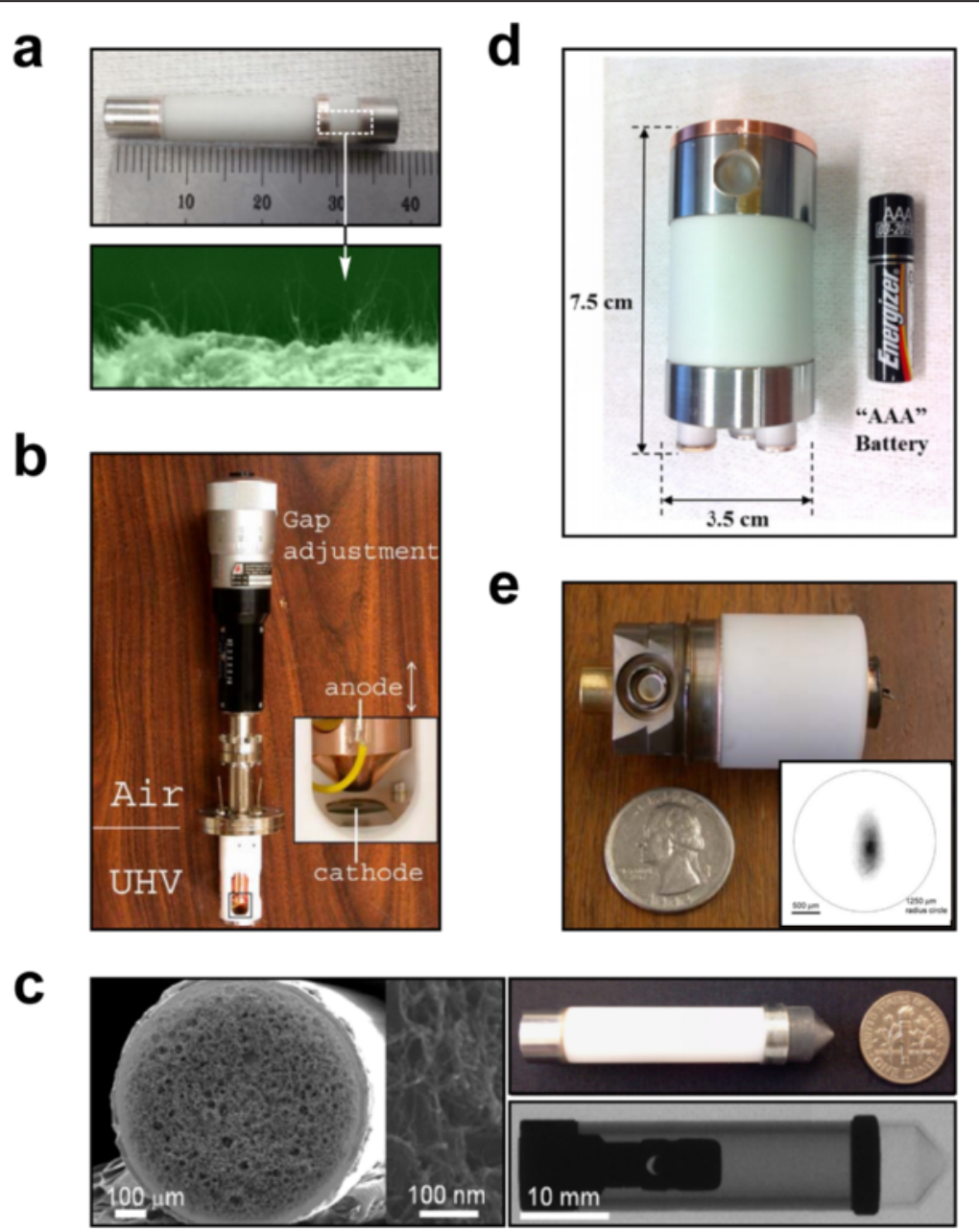

Figure 9 Miniature CNT-based FE X-ray sources. (a) A disordered miniature CNT, brazed triode X-ray source fabricated by ball milling, and firing of a CNT paste on the apex of a $0.6 \mathrm{~mm}$ Kovar rod, and operated at $12 \mathrm{kV}$ [244]. Copyright 2013, Electronics and Telecommunications Research Institute [208]. Copyright 2013, American Institute of Physics (b) A miniature X-ray source fabricated by thermal CVD capable of supporting current densities of up to $1 \mathrm{~A} / \mathrm{cm}^{2}$ [182]. Copyright 2004, Joint Committee on Powder Diffraction Standards. (c) A sintered SWCNT paste transmission-type miniature CNT cathode X-ray source, weighting $14.5 \mathrm{~g}$, and operating up to $70 \mathrm{kV}$ with uniform spatial dose distribution [207]. Copyright 2012, Springer. (d) A $7.5 \mathrm{~cm}$ long selaed CNT-based X-ray source operating at 30 kV. [154]. Copyright 2013, Society of Photo-Optical Instrumentation Engineers. (e) An Oxford Instruments X-ray Technology Inc. miniature field emission X-ray tube with gated MWCNT 2 mm diameter cathode. Adapted from [182]. Copyright 2004, Joint Committee on Powder Diffraction Standards. 
variation in the $\mathrm{X}$-ray dose. Radially, the X-ray dose rate was $108 \mathrm{~Gy} / \mathrm{min}$ and was broadly isotropic (20\% variation) with a typical focal spot size, as defined by EU standard EN 12543-5, of the order of 3-4 mm. Serious heating prevented the source from being operated for significant lengths of time at the maximum anode bias. Kim et al. [154], as shown in Figure 9(d), have developed a similar brazed compact sealed source, measuring just $3.5 \mathrm{~cm}$ in diameter and $7.5 \mathrm{~cm}$ in length. This pentode device - consisting of a cathode, gate, two focusing electrodes, and an anode - had a focal spot of the order of $300 \mu \mathrm{m}$ in diameter when operated with an anode current of $50 \mathrm{~mA}$. The CNT cathode was just $0.15 \mathrm{~cm}^{2}$ and was formed form a screen-printed and ball-milled complex CNT paste combined with inorganic fillers, oxides, metallic nano particles and a photo-initiator monomer with organic components including acrylates. The CNT films were relatively macroscopically uniform between samples, though rather perturbed and irreproducible microscopically. No active pumping system was integrated, though a non-evaporable getter was fabricated in an attempt to maintain the vacuum environment. The tube pressure was only of the order of $10^{-6}$ mbar upon sealing. The cavity pressure during emission was not noted. Pulse mode operation ( $10 \%$ duty cycle) was opted for - at $30 \mathrm{kV}$ and $10 \mathrm{~mA}$, to reduce thermally stimulated outgassing. Nevertheless, the tube still operated at approximately $200^{\circ} \mathrm{C}$ which almost certainly compromised the vacuum, even for a previously well-outgassed cathode assembly. Figure 9(e) shows the Oxford Instruments X-ray Technology Inc. miniature MWCNT FE X-ray tube with a $2 \mathrm{~mm}$ diameter cathode and integrated gate. The device develops a somewhat asymmetrical and diffuse focal spot with a major axis length of the order of $700 \mu \mathrm{m}$ [182].

\subsection{Commercial progress}

The published information from commercial work is, at present, quite limited, and is more prevalent among smaller emerging enterprises. Of the larger international conglomerates, Thales and Thales Electron Devices have been active for just over a decade in developing CNT photocathodes for optically driven multiple X-ray sources. No compact commercial system is though, as yet, available. Due to their novel micro- and nano-fabrication techniques the Thales systems have demonstrated very fast switching times and high bandwidth, though lower on-off current ratios $(\sim 10)$, relative to the conventional electronic methods [245,246]. Siemens has been investigating the development of fast CNT based tomographic systems, in particular for airport security scanners [247]. This followed a period as a joint venture partner in XinRay Ltd, (North Carolina, USA) who were simultaneously developing tomographic and tomosynthesis systems for medical applications such as mammography. Xintek, and its associate company of XinRay, have also been extensively involved with the manufacture of systems for static tomosynthesis using CNT FE sources [248]. In 2004, in collaboration with NASA and Microwave Power Technology Inc., Oxford Instruments published work on their research efforts towards a MWCNT-based miniature source with a claimed $80 \%$ efficiency [182]. To demonstrate the robustness of the source they operated them at $1.5 \mathrm{~W}$ for $>100,000$ pulses, each 10 s in duration (66\% duty cycle). Oxford Instruments have stated an on-going commitment towards the development micro focal CNT source, which they have implemented in their Eclipse II models. These miniature tubes are based on $3 \mathrm{~W}$ CNT field emitters with an integrated power supply. This small package is only $160 \times 38 \mathrm{~mm}$, with a mass of $300 \mathrm{~g}$ and is battery operated [182]. Nevertheless, commercial progress remains stilted at present with the incumbent TE market dominating. FE sources with significant functional and lifetime advances are needed, with manufacturing based on readily accessible, widely applicable, and inexpensive techniques.

\section{Conclusion}

Here we have reviewed the current state-of-the-art in carbon nanotube-based field emission X-ray sources. Issues from fabrication to functionality have been considered. The various systems demonstrated to date have been described, highlighting some of the technological barriers facing the technology. Compared to other electron emission materials, the potential of carbon nanotubes is largely unparalleled. Their attractive morphological and electronic properties are very promising for future electron source technologies. Within the coming decade there is the distinct possibility that FE electron sources will reach a level of technological maturity where they pose a distinct and real threat to incumbent thermionic sources. The high attainable current densities, rapid pulsing and multi-pixel potential, mediated by the ability to pattern at the submicron scale, will likely result in a number of persuasive proof-of-principle prototypes that will help disrupt the incumbent, yet technologically stagnated, thermionic source market. Significant further research is needed to realise this commercial potential. Nonetheless, it remains clear that carbon nanotube-based field emission X-ray sources have great prospects. Their intrinsic manufacturability and enhanced functionality will undoubtedly be key in realising a new generation of innovative X-ray scanning techniques, applicable across many fields and industries, which have hitherto been unavailable.

\section{Abbreviations}

$\beta$ : Field enhancement factor; FN: Fowler-Nordheim; $\mathrm{l}_{\mathrm{a}}$ : Anode current (A); J: Current density $\left(\mathrm{A} / \mathrm{cm}^{2}\right)$; FE: Field emission; PE: Photoelectric emission; TE: Thermionic emission; CNF: Carbon nanofibres; CNT: Carbon nanotubes; MWCNT: Multi-walled carbon nanotube; SWCNT: Single-walled carbon nanotube. 


\section{Competing interests}

The authors declare that they have no competing interests.

\section{Authors' contributions}

RJP and MTC contributed equally. RJP and MTC wrote the manuscript. MTC designed the figures. CMC compiled the materials summary. All authors reviewed and approved the manuscript.

\section{Authors' information}

Richard Parmee: Richard Parmee is a researcher in the Electrical Engineering Division, Department of Engineering, University of Cambridge, and the William Pitt Fellow at Pembroke College. He received the MA in Electrical Sciences from the University of Cambridge is currently researching the applications of field emission using Carbon Nanotubes, for X-ray generation, at the Centre for Advanced Photonics and Electronics in Cambridge. He is an engineer in the fields of image processing, automatic $X$-ray inspection and electronic gauging. He has worked extensively in the areas of precision measurement, statistical quality control and end-of-line inspection, and has developed X-ray applications, equipment, image processing and detector technology for many of the largest companies in the world in the food, medical and pharmaceutical industries

Clare Melissa Collins: Clare Collins is studying for the MRes in Ultra Precision funded by the EPSRC, at the University of Cambridge. She graduated from King's College London in 2013 with an MSci in Physics.

William Ireland Milne: William Milne was the head of the Electrical Engineering Division, Department of Engineering, University of Cambridge, from 1999-2014. He is a Professor in Electrical Engineering, and Director of the Centre for Advanced Photonics and Electronics where he heads the Electronic Devices and Materials group. He obtained his BSc from St Andrews University, Scotland, in 1970 and a PhD from Imperial College London in 1973. In his formative years he worked at the Plessey Res Co., UK following which time, in 1976, he joined the Department of Engineering, University of Cambridge. He is a Fellow of the Royal Academy of Engineering and was awarded the 2008 Institute of Engineering and Technology's JJ Thomson medal for his work on electronic materials. He is a Distinguished Visiting Scholar at KyungHee University, Korea, a Distinguished Visiting Professor at Southeast University, China, and a Guest Professor at Shizuoka University, Japan. His research focuses on large-area silicon and carbon-based thin film materials, their growth and application of carbon nanomaterials in electronics.

Matthew Thomas Cole: Matthew Cole is the Oppenheimer Research Fellow in the Department of Engineering, University of Cambridge, and Fellow of St Edmund's College, University of Cambridge. He is based in the Centre for Advanced Photonics and Electronics and is a member of the Cambridge Graphene Centre. He gained an MEng (Hons) in Engineering Sciences from Oxford University in 2008 and a PhD in Electrical Engineering from the University of Cambridge in 2011. He is a Fellow of the Institute of Nanotechnology, a Chartered Engineer, a Chartered Physicist, and a Chartered Scientist. He has spent time as a visiting scholar at Harvard University and as a research associate at Sharp Laboratories of Europe. His interests include the heterogeneous integration of chemical vapour deposited aligned nanomaterials for electron emission applications.

\section{Acknowledgements}

The author's thank Dr C. Li, Prof. W. Lei, and Prof. B.P. Wang of Southeast University, China, for their on-going collaboration. M.T.C. thanks the Winston Churchill Trust and the Oppenheimer Research Fellowship for generous financial support. This work was supported by an EPSRC Impact Acceleration grant and a TSB Advanced Materials Feasibility award.

\section{Received: 16 September 2014 Accepted: 6 October 2014} Published online: 06 January 2015

\section{References}

1. Roentgen, On a new kind of rays. Nature 53, 274-276 (1896)

2. JJ Thomson, The Röntgen rays. Nature 53, 581-583 (1896)

3. R Kienbock, Uber die Einwirkung des Rontgen-Lichtes auf die Haut. Wiener Kiin Wschr 13, 1153 (1900)

4. L Benoist, Experimental definition of various types of $X$-rays by the radiochromator. C R Acad Sci Puns 135, 225 (1902)

5. C Beck, Röntgen-ray diagnosis and therapy. Arch Roentgen Ray 9, 110-110 (1904)
6. WL Bragg, The diffraction of short electromagnetic waves by a crystal, in Proceedings of the Cambridge Philosophical Society, 1913, p. 4

7. M von Laue, Concerning the detection of X-ray interferences. Nobel lecture (1915), doi: 10.1002/adom.201400238

8. HG Moseley, XCIII, The high-frequency spectra of the elements. London Edinburgh Dublin Philos Mag J Sci 26, 1024-1034 (1913)

9. RE Franklin, RG Gosling, Molecular configuration in sodium thymonucleate. Nature 171, 740-741 (1953)

10. AH Compton, A quantum theory of the scattering of $X$-rays by light elements. Physical Review 21, 483 (1923)

11. AH Compton, On the mechanism of X-ray scattering. Proc Natl Acad Sci U S A 11, 303 (1925)

12. R Glocker, H Schreiber, Quantitative Röntgen spectrum analysis by means of cold cathode excitation. Ann Phys 85, 1089-1102 (1928)

13. CR Bull, R Zwiggelaar, RD Speller, Review of inspection techniques based on the elastic and inelastic scattering of $X$-rays and their potential in the food and agricultural industry. (J Food Eng 33, 167-179 (1997)

14. WD Coolidge, A powerful röntgen ray tube with a pure electron discharge Phys Rev 2, 409-430 (1913)

15. EL Murphy, RH Good, Thermionic emission, field emission, and the transition region. Phys Rev 102, 1464-1473 (1956)

16. W Lei, C Li, MT Cole, K Qu, S Ding, Y Zhang, JH Warner, X Zhang, B Wang, WI Milne, A graphene-based large area surface-conduction electron emission display. Carbon 56, 8 (2013)

17. RH Fowler, $L$ Nordheim, Electron emission in intense electric fields. Proc $R$ Soc Lond A Math Phys Character 119, 173-181 (1928)

18. WI Milne, KBK Teo, E Minoux, O Groening, L Gangloff, L Hudanski, J-P Schnell, D Dieumegard, F Peauger, IYY Bu, MS Bell, P Legagneux, G Hasko, GAJ Amaratunga, Aligned carbon nanotubes/fibers for applications in vacuum microwave amplifiers. J Vac Sci Technol B 24, 345-348 (2006)

19. P Hawkes, E Kasper, Principles of Electron Optics Vol. 2: Applied Geometrical Optics Academic (Academic Press, San Diego, 1996), pp. 953-970

20. CJ Edgcombe, U Valdrè, Field emission and electron microscopy. Microsc Microanal 6, 380-387 (2000)

21. J-M Bonard, T Stöckli, O Noury, A Châtelain, Field emission from cylindrica carbon nanotube cathodes: possibilities for luminescent tubes. Appl Phys Lett 78, 2775-2777 (2001)

22. WP Dyke, J Trolan, Field emission: large current densities, space charge, and the vacuum arc. Phys Rev 89, 799 (1953)

23. W Dyke, W Dolan, Field emission. Adv Electron Electron Phys 8, 89-185 (1956)

24. CA Spindt, A thin-film field-emission cathode. J Appl Phys 39, 3504-3505 (1968)

25. I Brodie, C Spindt, Advances in Electronics and Electron Physics edited by PW Hawkes, 83rd edn., 1992

26. CA Spindt, I Brodie, L Humphrey, ER Westerberg, Physical properties of thin-film field emission cathodes with molybdenum cones. J Appl Phys 47, 5248-5263 (1976)

27. CA Spindt, CE Holland, I Brodie, JB Mooney, ER Westerberg, Field-emitter arrays to vacuum fluorescent display. Electron Devices IEEE Trans 36, 225-228 (1989)

28. L Yukui, Z Changchun, L Xinghui, Field emission display with carbon nanotubes cathode: prepared by a screen-printing process. Diam Relat Mat 11, 1845-1847 (2002)

29. DR Whaley, BM Gannon, CR Smith, CM Armstrong, CA Spindt, Application of field emitter arrays to microwave power amplifiers. Plasma Sci IEEE Trans 28, 727-747 (2000)

30. H Makishima, S Miyano, H Imura, J Matsuoka, H Takemura, A Okamoto, Design and performance of traveling-wave tubes using field emitter array cathodes. Appl Surf Sci 146, 230-233 (1999)

31. KL Jensen, Field emitter arrays for plasma and microwave source applications. Phys Plasmas (1994-present) 6, 2241-2253 (1999)

32. KBK Teo, E Minoux, L Hudanski, F Peauger, JP Schnell, L Gangloff, P Legagneux, D Dieumegard, GAJ Amaratunga, WI Milne, Microwave devices - carbon nanotubes as cold cathodes. Nature 437, 968-968 (2005)

33. EF Barasch, HP Demroff, TS Elliott, TB Kasprowicz, B Lee, T Mazumdar, PM Mcintyre, Y Pang, DD Smith, H-J Trost Gated Field-Emitter Cathodes for High-Power Microwave Applications, in Proceedings of the 1992 Linear Accelerator Conference (Ottawa, Ontario, Canada, 1992)

34. MT Cole, Dry-Transfer of Chemical Vapour Deposited Nanocarbon Thins Films for Functionally Enhanced Flexible Transparent Electronics Applications (University of Cambridge, Cambridge, 2011) 
35. JJ Chiu, WS Wang, CC Kei, CP Cho, TP Perng, PK Wei, SY Chiu, Room temperature vibrational photoluminescence and field emission of nanoscaled tris-(8-hydroxyquinoline) aluminum crystalline film. Appl Phys Lett 83, 4607-4609 (2003)

36. C-P Cho, T-P Perng, On the dendritic growth and field emission of amorphous AIQ3 nanowires. Org Electron 11, 115-122 (2010)

37. X Fang, Y Bando, UK Gautam, C Ye, D Golberg, Inorganic semiconductor nanostructures and their field-emission applications. J Mater Chem 18, 509-522 (2008)

38. FCK Au, KW Wong, YH Tang, YF Zhang, I Bello, ST Lee, Electron field emission from silicon nanowires. Appl Phys Lett 75, 1700-1702 (1999)

39. Y Jr Hung, S-L Lee, LC Beng, H-C Chang, Y-J Huang, K-Y Lee, Y-S Huang, Relaxing the electrostatic screening effect by patterning vertically-aligned silicon nanowire arrays into bundles for field emission application. Thin Solid Films 556, 146-154 (2014)

40. LA Ma, ZX Lin, JY Lin, YA Zhang, LQ Hu, TL Guo, Large-scale growth of ultrathin $\mathrm{MgO}$ nanowires and evaluate their field emission properties. Physica $\mathrm{E}$ 41, 1500-1503 (2009)

41. H Tan, N Xu, S Deng, Synthesis and electron emission properties of MgO nanowires. J Vac Sci Technol B 28, C2B20-C22B23 (2010)

42. JH He, RS Yang, YL Chueh, LJ Chou, LJ Chen, ZL Wang, Aligned AIN nanorods with multi-tipped surfaces - growth, field-emission, and cathodoluminescence properties. Adv Mater 18, 650 (2006)

43. X Ji, P Chen, J Deng, W Zhou, F Chen, Field emission properties of AIN nanostructures. J Nanosci Nanotechno 12, 6531-6533 (2012)

44. J Pelletier, D Gervais, C Pomot, Application of wide-gap semiconductors to surface ionization: work functions of AIN and SiC single crystals. J Appl Phys 55, 994-1002 (1984)

45. W Sun, Y Li, Y Yang, Y Li, C Gu, J Li, Morphology inducing selective plasma etching for AIN nanocone arrays: tip-size dependent photoluminescence and enhanced field emission properties. J Mater Chem C 2, 2417-2422 (2014)

46. PG Chavan, MA More, DS Joag, SS Badadhe, IS Mulla, Photo-enhanced field emission studies of tapered CdS nanbelts, in Proceedings $27^{\text {th }}$ International Vacuum Nanoelectronics Conference (IEEE, Engelberg, Switzerland, 2014), pp. 83-84

47. P Chavan, R Kashid, S Badhade, I Mulla, M More, D Joag, CdS nanowires: ultra-long growth and enhanced field emission properties. Vacuum 101, 38-45 (2014)

48. T Ge, L Kuai, B Geng, Solution-phase chemical route to branched singlecrystalline CdS nanoarchitectures and their field emission property. J Alloys Compd 509, L353-L358 (2011)

49. Y Lin, Y Hsu, S Lu, S Kung, Non-catalytic and template-free growth of aligned CdS nanowires exhibiting high field emission current densities. Chem Commun, 2391-2393 (2006); doi: 10.1039/b604309g

50. YH Lee, CH Choi, YT Jang, EK Kim, BK Ju, NK Min, JH Ahn, Tungsten nanowires and their field electron emission properties. Appl Phys Lett 81, 745-747 (2002)

51. S Wang, Y He, X Fang, J Zou, Y Wang, H Huang, PMFJ Costa, M Song, B Huang, CT Liu, PK Liaw, Y Bando, D Golberg, Structure and field-emission properties of sub-micrometer-sized tungsten-whisker arrays fabricated by vapor deposition. Adv Mater 21, 2387 (2009)

52. KS Yeong, JTL Thong, Field-emission properties of ultrathin $5 \mathrm{~nm}$ tungsten nanowire. J Appl Phys 100, 114325 (2006)

53. N Wan, J Xu, G Chen, X Gan, S Guo, L Xu, K Chen, Broadband anti-reflection and enhanced field emission from catalyst-free grown small-sized ITO nanowires at a low temperature. Acta Mater 58, 3068-3072 (2010)

54. AS Komolov, EF Lazneva, SA Pshenichnyuk, AA Gavrikov, NS Chepilko, AA Tomilov, NB Gerasimova, AA Lezov, PS Repin, Electronic properties of the interface between hexadecafluoro copper phthalocyanine and unsubstituted copper phthalocyanine films. Semiconductors 47, 956-961 (2013)

55. WY Tong, ZX Li, AB Djurisic, WK Chan, SF Yu, Field emission from copper phthalocyanine and copper hexadecafluorophthalocyanine nanowires. Mater Lett 61, 3842-3846 (2007)

56. S-H Jang, J-S Jang, Schottky barrier characteristics and carrier transport mechanism for ohmic contacts to strained p-Type InGaN/GaN superlattice. Electrochem Solid State Lett 13, H403-H405 (2010)

57. TH Seo, KJ Lee, TS Oh, YS Lee, H Jeong, AH Park, H Kim, YR Choi, E-K Suh, TV Cuong, VH Pham, JS Chung, EJ Kim, Graphene network on indium tin oxide nanodot nodes for transparent and current spreading electrode in InGaN/GaN light emitting diode. Appl Phys Lett 98, 251114 (2011)

58. F Ye, XM Cai, XM Wang, EQ Xie, The growth and field electron emission of InGaN nanowires. J Crsy Growth 304, 333-337 (2007)
59. J Lee, Y Jung, J Song, JS Kim, G-W Lee, HJ Jeong, Y Jeong, High-performance field emission from a carbon nanotube carpet. Carbon 50, 3889-3896 (2012)

60. JM Bonard, JP Salvetat, T Stockli, L Forro, A Chatelain, Field emission from carbon nanotubes: perspectives for applications and clues to the emission mechanism. Appl Phys A Mater 69, 245-254 (1999)

61. DD Nguyen, Y-T Lai, N-H Tai, Enhanced field emission properties of a reduced graphene oxide/carbon nanotube hybrid film. Diam Relat Mat 47, 1-6 (2014)

62. M Shiraishi, M Ata, Work function of carbon nanotubes. Carbon 39, 1913-1917 (2001)

63. H Ago, T Kugler, F Cacialli, WR Salaneck, MSP Shaffer, AH Windle, RH Friend, Work functions and surface functional groups of multiwall carbon nanotubes. J Phys Chem B 103, 8116-8121 (1999)

64. K Zheng, X Li, X Mo, G Chen, Z Wang, G Chen, Enhanced field emission and patterned emitter device fabrication of metal-tetracyanoquinodimethane nanowires array. Appl Surf Sci 256, 2764-2768 (2010)

65. O Auciello, JC Tucek, AR Krauss, DM Gruen, N Moldovan, DC Mancini, Review of synthesis of low-work function Cu-Li alloy coatings and characterization of the field emission properties for application to field emission devices. J Vac Sci Technol B 19, 877-883 (2001)

66. T Glatzel, H Steigert, S Sadewasser, R Klenk, MC Lux-Steiner, Potential distribution of $\mathrm{Cu}(\mathrm{In}, \mathrm{Ga})(\mathrm{S}, \mathrm{Se})(2)$-solar cell cross-sections measured by Kelvin probe force microscopy. Thin Solid Films 480, 177-182 (2005)

67. S Ding, H Cui, W Lei, X Zhang, B Wang, Stable field emission from ZnO nanowires grown on 3D graphene foam, in Proceedings $27^{\text {th }}$ International Vacuum Nanoelectronics Conference (IEEE, Engelberg, Switzerland, 2014), pp. 178-179

68. F Jamali Sheini, DS Joag, MA More, Field emission studies on electrochemically synthesized ZnO nanowires. Ultramicroscopy 109, 418-422 (2009)

69. X Sun, Designing efficient field emission into $\mathrm{ZnO}$ using morphological and electronic design techniques, low-threshold, high-emission current densities have been obtained with ZnO. SPIE. Nanotechnology (2006)

70. H Tampo, H Shibata, K Maejima, TW Chiu, H Itoh, A Yamada, K Matsubara, P Fons, Y Chiba, T Wakamatsu, Y Takeshita, H Kanie, S Niki, Band profiles of $\mathrm{ZnMgO/ZnO}$ heterostructures confirmed by Kelvin probe force microscopy. Appl Phys Lett 94, 242107 (2009)

71. YH Yang, CX Wang, B Wang, NS Xu, GW Yang, ZnO nanowire and amorphous diamond nanocomposites and field emission enhancement. Chem Phys Lett 403, 248-251 (2005)

72. ZP Zhang, WQ Chen, YF Li, J Chen, Defect-Assisted Field Emission fron ZnO nanotrees, in Proceedings $27^{\text {th }}$ International Vacuum Nanoelectronics Conference (Elsevier, Engelberg, Switzerland, 2005), pp. 78-79

73. DKT Ng, MH Hong, LS Tan, YW Zhu, CH Sow, Field emission enhancement from patterned gallium nitride nanowires. Nanotech 18, (2007); doi: 10.1088/ 0957-4484/18/37/375707

74. YQ Wang, RZ Wang, MK Zhu, BB Wang, B Wang, H Yan, Structure and surface effect of field emission from gallium nitride nanowires. Appl Surf Sci 285(Part B), 115-120 (2013)

75. R Yousefi, FJ Sheini, MR Muhamad, MA More, Characterization and field emission properties of $\mathrm{ZnMgO}$ nanowires fabricated by thermal evaporation process. Solid State Sci 12, 1088-1093 (2010)

76. A Agiral, JGE Gardeniers, On-Chip Tungsten Oxide Nanowires Based Electrodes for Charge Injection, 2010

77. K Huang, Q Pan, F Yang, S Ni, D He, The catalyst-free synthesis of large-area tungsten oxide nanowire arrays on ITO substrate and field emission properties. Mater Res Bull 43, 919-925 (2008)

78. Y Kojima, K Kasuya, T Ooi, K Nagato, K Takayama, M Nakao, Effects of oxidation during synthesis on structure and field-emission property of tungsten oxide nanowires. Jpn J Appl Phys 46, 6250-6253 (2007)

79. S Yue, H Pan, Z Ning, J Yin, Z Wang, G Zhang, Amazing ageing property and in situ comparative study of field emission from tungsten oxide nanowires. Nanotech 22, (2011); doi: 10.1088/0957-4484/22/11/115703

80. A Khademi, R Azimirad, AA Zavarian, AZ Moshfegh, Growth and field emission study of molybdenum oxide nanostars. J Phys Chem C 113, 19298-19304 (2009)

81. J Zhou, Large-area nanowire arrays of molybdenum and molybdenum oxides: synthesis and field emission properties. Advanced Mater 15, 1835-1840 (2003)

82. J Liu, Z Zhang, C Pan, Y Zhao, X Su, Y Zhou, D Yu, Enhanced field emission properties of $\mathrm{MoO} 2$ nanorods with controllable shape and orientation. Mater Lett 58, 3812-3815 (2004)

83. X Fang, Y Bando, G Shen, C Ye, UK Gautam, PMFJ Costa, C Zhi, C Tang, D Golberg, Ultrarine ZnS nanobelts as field emitters. Adv Mater 19, 2593 (2007) 
84. RV Kashid, DJ Late, SS Chou, Y-K Huang, D Mrinmoy, DS Joag, MA More, VP Dravid, Enhanced field-emission behavior of layered MoS2 sheets. Small 9, 2730-2734 (2013)

85. T Yamada, T Masuzawa, T Ebisudani, K Okano, T Taniguchi, Field emission characteristics from graphene on hexagonal boron nitride. Appl Phys Lett 104, 5 (2014)

86. T Yamada, T Ebisudani, K Okana, T Masuzawa, Y Neo, H Mimura, T Taniguchi, Field emission characteristics of graphene/h-BN structure, in Proceedings $27^{\text {th }}$ International Vacuum Nanoelectronics Conference (IEEE, Engelberg, Switzerland, 2014), pp. 182-183

87. AB Preobrajenski, AS Vinogradov, N Martensson, Monolayer of h-BN chemisorbed on $\mathrm{Cu}(111)$ and $\mathrm{Ni}(111)$ : the role of the transition metal $3 \mathrm{~d}$ states. Surf Sci 582, 21-30 (2005)

88. S Ohtani, T Yano, S Kondo, Y Kohno, Y Tomita, Y Maeda, K Kobayashi, Electron emission from h-BN films codoped with $\mathrm{Mg}$ and $\mathrm{O}$ atoms. Thin Solid Films 546, 53-57 (2013)

89. W Chen, Y Su, H Chen, S Deng, N Xu, J Chen, Temperature Dependence of the Field Emission from Monolayer Graphene, in Proceedings $27^{\text {th }}$ International Vacuum Nanoelectronics Conferernce (IEEE, Engelberg, Switzerland, 2014), pp. 36-37

90. T Hallam, MT Cole, WI Milne, GS Duesberg, Field emission characteristics of contact printed graphene fins. Small 10, 95-99 (2014)

91. Z-S Wu, S Pei, W Ren, D Tang, L Gao, B Liu, F Li, C Liu, H-M Cheng, Field emission of single-layer graphene films prepared by electrophoretic deposition. Adv Mater 21, 1756-1760 (2009)

92. C Wu, F Li, Y Zhang, T Guo, Field emission from vertical graphene sheets formed by screen-printing technique. Vacuum 94, 48-52 (2013)

93. A Malesevic, R Kemps, A Vanhulsel, MP Chowdhury, A Volodin, C Van Haesendonck, Field emission from vertically aligned few-layer graphene. J Appl Phys 104, 084301 (2008)

94. UA Palnitkar, RV Kashid, MA More, DS Joag, LS Panchakarla, CNR Rao, Remarkably low turn-on field emission in undoped, nitrogen-doped, and boron-doped graphene. Appl Phys Lett 97, 063102 (2010)

95. L Li, W Sun, S Tian, X Xia, J Li, C Gu, Floral-clustered few-layer graphene nanosheet array as high performance field emitter. Nanoscale 4, 6383-6388 (2012)

96. S Pandey, P Rai, S Patole, F Gunes, G-D Kwon, J-B Yoo, P Nikolaev, S Arepalli, Improved electron field emission from morphologically disordered monolayer graphene. Appl Phys Lett 100, 043104 (2012)

97. L Jiang, T Yang, F Liu, J Dong, Z Yao, C Shen, S Deng, N Xu, Y Liu, H-J Gao, Controlled synthesis of large-scale, uniform, vertically standing graphene for high-performance field emitters. Adv Mater 25, 250-255 (2013)

98. ATH Chuang, J Robertson, BO Boskovic, KKK Koziol, Three-dimensional carbon nanowall structures. Appl Phys Lett 90, 123107 (2007)

99. D Banerjee, S Mukherjee, KK Chattopadhyay, Synthesis of amorphous carbon nanowalls by DC-PECVD on different substrates and study of its field emission properties. Appl Surf Sci 257, 3717-3722 (2011)

100. YH Wu, BJ Yang, BY Zong, H Sun, ZX Shen, YP Feng, Carbon nanowalls and related materials. J Mater Chem 14, 469-477 (2004)

101. CS Rout, PD Joshi, RV Kashid, DS Joag, MA More, AJ Simbeck, M Washington, SK Nayak, DJ Late, Superior field emission properties of layered WS2-RGO nanocomposites. Sci Rep 3, (2013); doi: 10.1038/srep03282

102. M-C Kan, J-L Huang, JC Sung, K-H Chen, B-S Yau, Thermionic emission of amorphous diamond and field emission of carbon nanotubes. Carbon 41, 2839-2845 (2003)

103. A Yutani, A Kobayashi, A Kinbara, Work functions of thin LaB6 films. Appl Surf Sci 70-71(Part 2), 737-741 (1993)

104. RP Menaka, S Ghosh, AK Ganguli, Manipulating the anisotropy and field emission of lanthanum hexaboride nanorods. RSC Adv 2, 7875-7885 (2012)

105. M Jha, R Patra, S Ghosh, AK Ganguli, Vertically aligned nanorods of lanthanum hexaboride with efficient field emission properties. Sol State Comms 153, 35-39 (2013)

106. J Xu, G Hou, H Li, T Zhai, B Dong, H Yan, Y Wang, B Yu, Y Bando, D Golberg, Fabrication of vertically aligned single-crystalline lanthanum hexaboride nanowire arrays and investigation of their field emission. NPG Asia Mater 5, e53 (2013)

107. S Raina, WP Kang, JL Davidson, Field emission from nanodiamond grown with 'ridge' type geometrically enhanced features. Diam Relat Mat 17, 790-793 (2008)

108. B-R Huang, S Jou, T-C Lin, Y-K Yang, C-H Chou, Y-M Wu, Field emission property of arrayed nanocrystalline diamond. Diam Relat Mat 20, 314-317 (2011)

109. HS Jung, HH Park, SS Pang, SY Lee, The structural and electron field emission characteristics of pulsed laser deposited diamond-like carbon films with thermal treatment. Thin Solid Films 355, 151-156 (1999)
110. H Zanin, PW May, MHMO Hamanaka, EJ Corat, Field emission from hybrid diamond-like carbon and carbon nanotube composite structures. ACS Appl Mater Interfaces 5, 12238-12243 (2013)

111. D Banerjee, A Jha, KK Chattopadhyay, Low-temperature synthesis of amorphous carbon nanoneedle and study on its field emission property. Physica E 41, 1174-1178 (2009)

112. RK Tripathi, OS Panwar, AK Srivastava, I Rawal, S Chockalingam, Structural, nanomechanical, field emission and ammonia gas sensing properties of nitrogenated amorphous carbon films deposited by filtered anodic jet carbon arc technique. Talanta 125, 276-283 (2014)

113. J Robertson, Mechanisms of electron field emission from diamond, diamondlike carbon, and nanostructured carbon. J Vac Sci Tech B 17, 659-665 (1999)

114. A Hart, BS Satyanarayana, WI Milne, J Robertson, Effect of surface treatment and back contact material on field emission from tetrahedral amorphous carbon. Diam Relat Mat 8, 809-813 (1999)

115. A llie, A Hart, AJ Flewitt, J Robertson, WI Milne, Effect of work function and surface microstructure on field emission of tetrahedral amorphous carbon. J Appl Phys 88, 6002-6010 (2000)

116. WI Milne, Field emission from tetrahedrally bonded amorphous carbon. Appl Surf Sci 146, 262-268 (1999)

117. M Setvín, J Javorský, D Turčinková, I Matolínová, P Sobotík, P Kocán, O t'ádal, Ultrasharp tungsten tips-characterization and nondestructive cleaning. Ultramicroscopy 113, 152-157 (2012)

118. KL Ng, J Yuan, JT Cheung, KW Cheah, Electron field emission characteristics of electrochemical etched Si tip array. Sol State Comms 123, 205-207 (2002)

119. ZX Pan, JC She, SZ Deng, NS Xu, Si Tip Arrays with Ultra-Narrow Nanoscale Charge Transfer Channel, in Proceedings $27^{\text {th }}$ International Vacuum Nanoelectronics Conference (IEEE, Engelberg, Switzerland, 2014), pp. 74-75

120. SX Chen, JJ Li, CZ Gu, leee, Field Emission from the Composite Structure of Silicon Tips and Vertical Carbon Nanotubes, in 2007 7th leee Conference on Nanotechnology, Vol 1-3, 2007, pp. 367-370

121. JW Glesener, HB Lin, AA Morrish, Field emission from cleaved diamond fibers. Thin Solid Films 308, 204-208 (1997)

122. H-F Cheng, K-Y Teng, H-C Chen, G-C Tzeng, C-Y Tang, IN Lin, Bias enhanced nucleation and growth processes for improving the electron field emission properties of diamond films. Surf Coat Technol 228, S175-S178 (2013)

123. F Zhao, Z D-d, W S-I, C G-a, Z R-t, Diamond-like carbon decoration enhances the field electron emission of silicon nanowires. Surf Coat Technol 228, S349-S353 (2013)

124. K Panda, KJ Sankaran, BK Panigrahi, N-H Tai, IN Lin, Direct observation and mechanism for enhanced electron emission in hydrogen plasma-treated diamond nanowire films. ACS Appl Mater Interfaces 6, 8531-8541 (2014)

125. P Abbott, ED Sosa, DE Golden, Effect of average grain size on the work function of diamond films. Appl Phys Lett 79, 2835-2837 (2001)

126. X Song, CX Zhao, JQ Wu, J Chen, Field emission from copper micro-cones formed by ion bombardment of copper substrate using an oxide masking, in 25th International Vacuum Nanoelectronics Conference (IVNC) (IEEE, Jeju Island, South Korea, 2012), pp. 376-377

127. J Wang, L Wei, L Zhang, J Zhang, H Wei, C Jiang, Y Zhang, Controlled growth of nickel nanocrystal arrays and their field electron emission performance enhancement via removing adsorbed gas molecules. Crystengcomm 15, 1296-1306 (2013)

128. E Le Shim, SB Lee, E You, CJ Kang, KW Lee, YJ Choi, Rapid Fabrication of Wafer Scale Patterned Nickel Nanocone Arrays for Field Emission Applications, in 25th International Vacuum Nanoelectronics Conference (IVNC) (IEEE, Jeju Island, South Korea, 2012), pp. 198-199

129. SW Joo, AN Banerjee, Field emission characterization of vertically oriented uniformly grown nickel nanorod arrays on metal-coated silicon substrate. J Appl Phys 107, 114317 (2010)

130. T Nakane, K Sano, A Sakai, A Magosakon, K Yanagimoto, T Sakata, Fieldemission barrier height of an alloy tip: possible effect of surface segregation. J Vac Sci Tech A 15, 1563-1567 (1997)

131. J Wang, T Ito, Improved field emission characteristics of nano-structured carbon films deposited on polycrystalline CVD diamond. Diam Relat Mat 16, 364-368 (2007)

132. JB Cui, J Ristein, M Stammler, K Janischowsky, G Kleber, L Ley, Hydrogen termination and electron emission from CVD diamond surfaces: a combined secondary electron emission, photoelectron emission microscopy, photoelectron yield, and field emission study. Diam Relat Mat 9, 1143-1147 (2000)

133. O Gröning, Properties and characterization of chemical vapor deposition diamond field emitters. Solid-State Electron 45, 929-944 (2001) 
134. S lijima, Helical microtubules of graphitic carbon. Nature 354, 56-58 (1991)

135. A Oberlin, M Endo, T Koyama, Filamentous growth of carbon through benzene decomposition. J Crystal Growth 32, 335-349 (1976)

136. LA Chernozatonskii, YV Gulyaev, ZJ Kosakovskaja, NI Sinitsyn, GV Torgashov, YF Zakharchenko, EA Fedorov, VP Val'chuk, Electron field emission from nanofilament carbon films. Chem Phys Lett 233, 63-68 (1995)

137. A Rinzler, J Hafner, P Nikolaev, L Lou, S Kim, D Tomanek, P Nordlander, D Colbert, R Smalley, Unraveling nanotubes: field emission from an atomic wire. Science 269, 1550-1553 (1995)

138. N de Jonge, Y Lamy, K Schoots, TH Oosterkamp, High brightness electron beam from a multi-walled carbon nanotube. Nature 420, 393-395 (2002)

139. S Akita, H Nishijima, Y Nakayama, F Tokumasu, K Takeyasu, Carbon nanotube tips for a scanning probe microscope: their fabrication and properties. J Phys D 32, 1044 (1999)

140. M Mann, K Teo, W Milne, T Tessner, Direct growth of multi-walled carbon nanotubes on sharp tips for electron microscopy. NANO 1, 35-39 (2006)

141. H Nishijima, S Kamo, S Akita, Y Nakayama, KI Hohmura, SH Yoshimura, K Takeyasu, Carbon-nanotube tips for scanning probe microscopy: preparation by a controlled process and observation of deoxyribonucleic acid. Appl Phys Lett 74, 4061-4063 (1999)

142. W Milne, K Teo, Growth and characterization of carbon nanotubes for field-emission-display applications. J Soc Inf Display 12, 289-292 (2004)

143. W Choi, D Chung, J Kang, H Kim, Y Jin, I Han, Y Lee, J Jung, N Lee, G Park, Fully sealed, high-brightness carbon-nanotube field-emission display. Appl Phys Lett 75, 3129-3131 (1999)

144. N Lee, D Chung, I Han, J Kang, Y Choi, H Kim, S Park, Y Jin, W Yi, M Yun, Application of carbon nanotubes to field emission displays. Diamond Relat Mater 10, 265-270 (2001)

145. KBK Teo, M Chhowalla, GAJ Amaratunga, WI Milne, P Legagneux, G Pirio, L Gangloff, D Pribat, V Semet, VT Binh, WH Bruenger, J Eichholz, H Hanssen, D Friedrich, SB Lee, DG Hasko, H Ahmed, Fabrication and electrical characteristics of carbon nanotube-based microcathodes for use in a parallel electron-beam lithography system. J Vac Sci Tech B 21, 693-697 (2003)

146. J Nd, J-M Bonard, Carbon nanotube electron sources and applications. Philos Transact Math Phys Eng Sci 362, 2239-2266 (2004)

147. SM Vieira, KB Teo, WI Milne, O Gröning, L Gangloff, E Minoux, P Legagneux, Investigation of field emission properties of carbon nanotube arrays defined using nanoimprint lithography. Appl Phys Lett 89, 022111 (2006)

148. H Sugie, M Tanemura, V Filip, K Iwata, K Takahashi, F Okuyama, Carbon nanotubes as electron source in an x-ray tube. Appl Phys Lett 78, 2578-2580 (2001)

149. GZ Yue, Q Qiu, B Gao, Y Cheng, J Zhang, H Shimoda, S Chang, JP Lu, O Zhou, Generation of continuous and pulsed diagnostic imaging X-ray radiation using a carbon-nanotube-based field-emission cathode. Appl Phys Lett 81, 355-357 (2002)

150. A Haga, S Senda, Y Sakai, Y Mizuta, S Kita, F Okuyama, A miniature x-ray tube. Appl Phys Lett 84, 2208-2210 (2004)

151. S Senda, M Tanemura, Y Sakai, Y Ichikawa, S Kita, T Otsuka, A Haga, F Okuyama, New field-emission x-ray radiography system. Rev Sci Instrum 75, 1366-1368 (2004)

152. F Charbonnier, Developing and using the field emitter as a high intensity electron source. Appl Surf Sci 94, 26-43 (1996)

153. Y Iwai, T Koike, Y Hayama, A Jyouzuka, T Nakamura, Y Onizuka, M Miyoshi, $\mathrm{H}$ Mimura, Field emission characteristics of inflamed graphite at high temperature and its applications, in Technical Digest of IVNC, 2012, pp. 274-275

154. J-W Kim, J-W Jeong, J-T Kang, S Choi, J Choi, S Ahn, S Y-h, A digital compact $\mathrm{x}$-ray tube with carbon nanotube field emitters for advanced imaging systems, in SPIE Medical Imaging (International Society for Optics and Photonics, Nishikawa, 2013), pp. 861-866, From Conference Volume 8668, Medical Imaging 2013: Physics of Medical Imaging, Robert M. Nishikawa; Bruce R. Whiting, Lake Buena Vista (Orlando Area), Florida, USA | February 09, 2013

155. Y Saito, Carbon Nanotube and Related Field Emitters: Fundamentals and Applications (Wiley-VCH Verlag, Weinheim, 2010)

156. Y Cheng, O Zhou, Electron field emission from carbon nanotubes. Comptes Rendus Physique 4, 1021-1033 (2003)

157. I Oxford, Cold Cathode vs Thermionic X-ray Tubes [Online], 2000. http://wigner. elte.hu/koltai/science/pub/Which_Source_Cold_cathode_or_Thermionic.pdf

158. HY Choi, WS Chang, HS Kim, YH Park, JU Kim, Acquisition of X-ray images by using a CNT cold emitter. Phys Lett A 357, 36-41 (2006)

159. J Zhang, Y Cheng, YZ Lee, B Gao, Q Qiu, WL Lin, D Lalush, JP Lu, O Zhou, A nanotube-based field emission $\mathrm{x}$-ray source for microcomputed tomography. Rev Sci Instrum 76, $094301-094304$ (2005)
160. X Calderón-Colón, H Geng, B Gao, L An, G Cao, O Zhou, A carbon nanotube field emission cathode with high current density and long-term stability. Nanotech 20, 325707 (2009)

161. G Pirio, P Legagneux, D Pribat, K Teo, M Chhowalla, G Amaratunga, W Milne, Fabrication and electrical characteristics of carbon nanotube field emission microcathodes with an integrated gate electrode. Nanotechnology 13, 1 (2002)

162. D Temple, Recent progress in field emitter array development for high performance applications. Mat Sci Eng R Rep 24, 185-239 (1999)

163. SH Heo, A Ihsan, SO Cho, Transmission-type microfocus $x$-ray tube using carbon nanotube field emitters. Appl Phys Lett 90, 183109 (2007)

164. WI Milne, Q Zhang, Advances in Nanodevices and Nanofabrication (Pan Stanford Publishing, Singapore, 2012)

165. MT Cole, T Hallam, WI Milne, GS Duesberg, Field Emission Characteristics of Contact Printed Graphene Fins. Small, 2013

166. KBK Teo, SB Lee, M Chhowalla, V Semet, VT Binh, O Groening, M Castignolles, A Loiseau, G Pirio, P Legagneux, D Pribat, DG Hasko, H Ahmed, GAJ Amaratunga, WI Milne, Plasma enhanced chemical vapour deposition carbon nanotubes/ nanofibres - how uniform do they grow? Nanotech 14, 204-211 (2003)

167. B Gao, GZ Yue, Q Qiu, Y Cheng, H Shimoda, L Fleming, O Zhou, Fabrication and electron field emission properties of carbon nanotube films by electrophoretic deposition. Adv Mater 13, 1770-1773 (2001)

168. AR Boccaccini, J Cho, JA Roether, BJ Thomas, E Jane Minay, MS Shaffer, Electrophoretic deposition of carbon nanotubes. Carbon 44, 3149-3160 (2006)

169. S Wang, X Calderon, R Peng, EC Schreiber, O Zhou, S Chang, A carbon nanotube field emission multipixel $X$-ray array source for microradiotherapy application. Appl Phys Lett 98, 213701-213703 (2011)

170. J Li, W Lei, X Zhang, X Zhou, Q Wang, Y Zhang, B Wang, Field emission characteristic of screen-printed carbon nanotube cathode. Appl Surf Sci 220, 96-104 (2003)

171. F Sprenger, X Calderon, E Gidcumb, J Lu, X Qian, D Spronk, A Tucker, G Yang, O Zhou, Stationary digital breast tomosynthesis with distributed field emission x-ray tube, 2011. pp 79615I-79615I-79616

172. MT Cole, M Doherty, R Parmee, P Dawson, WI Milne, Ultra-broadband polarisers based on metastable free-standing aligned carbon nanotube membranes. Adv Opt Mater (2014), doi: 10.1002/adom.201400238

173. M Qian, T Feng, K Wang, H Ding, Y Chen, Q Li, Z Sun, Field emission of carbon nanotube films fabricated by vacuum filtration. Physica E 43, 462-465 (2010)

174. Y Cho, H Song, G Choi, D Kim, A simple method to fabricate high-performance carbon nanotube field emitters. J Electroceram 17, 945-949 (2006)

175. YS Shi, C-C Zhu, W Qikun, L Xin, Large area screen-printing cathode of CNT for FED. Diam Relat Mat 12, 1449-1452 (2003)

176. J-Y Pan, C-y Chen, Y-L Gao, C-C Zhu, Improved field emission characteristics of screen-printed CNT-FED cathode by interfusing Fe/Ni nano-grains. Displays 30, 114-118 (2009)

177. H-Y Shin, W-S Chung, KH Kim, Y-R Cho, B-C Shin, Effects of bonding materials in screen-printing paste on the field-emission properties of carbon nanotube cathodes. J Vac Sci Technol B 23, 2369-2372 (2005)

178. J-W Kim, J-W Jeong, J-T Kang, S Choi, S Ahn, Y-H Song, Highly reliable field electron emitters produced from reproducible damage-free carbon nanotube composite pastes with optimal inorganic fillers. Nanotechnology 25, 065201 (2014)

179. K Yamamoto, S Akita, Y Nakayama, Orientation and purification of carbon nanotubes using ac electrophoresis. J Phys D 31, 34-36 (1998)

180. K Yamamoto, S Akita, Y Nakayama, Orientation of carbon nanotubes using electrophoresis. Japanese J Appl Phys 35, L917 (1996)

181. MT Cole, C Collins, R Parmee, C Li, WI Milne, NanoCarbon Electron Emitters: Advances \& Applications, in Chemical Functionalisation of Carbon Nanomaterials: Chemistry \& Applications - Structure \& Synthesis (Taylor \& Francis, Philadelphia, 2015)

182. P Sarrazin, D Blake, L Delzeit, M Meyyappan, B Boyer, S Snyder, B Espinosa, Carbon-nanotube field emission $x$-ray tube for space exploration XRD/XRF instrument. Adv X Ray Anal 47, 8 (2004)

183. MT Cole, C Li, Y Zhang, SG Shivareddy, JS Barnard, W Lei, B Wang, D Pribat, GAJ Amaratunga, WI Milne, Hot electron field emission via individually transistor-ballasted carbon nanotube arrays. ACS Nano 6, 3236-3242 (2012)

184. HS Kim, D Quang, JH Kim, HJ Lee, DM Yoon, SS Shin, JW Ha, KJ Lee, YG Hwang, CH Lee, Field-emission electron source using carbon nanotubes for X-ray tubes. J Korean Phys Soc 52, 3 (2008)

185. MT Cole, KBK Teo, O Groening, L Gangloff, P Legagneux, WI Milne, Deterministic cold cathode electron emission from carbon nanofibre arrays. Sci Rep 4, (2014); doi: 10.1038/srep04840 
186. O Gröning, O Küttel, C Emmenegger, P Gröning, L Schlapbach, Field emission properties of carbon nanotubes. J Vac Sci Technol B 18, 665-678 (2000)

187. L Nilsson, O Groening, C Emmenegger, O Kuettel, E Schaller, L Schlapbach, $\mathrm{H}$ Kind, J Bonard, K Kern, Scanning field emission from patterned carbon nanotube films. Appl Phys Lett 76, 2071-2073 (2000)

188. S Fujii, H S-i, H Machida, H Kawai, K Ishida, M Katayama, H Furuta, T Hirao, $K$ Oura, Efficient field emission from an individual aligned carbon nanotube bundle enhanced by edge effect. Appl Phys Lett 90, 153108 (2007)

189. JL Killian, NB Zuckerman, DL Niemann, BP Ribaya, M Rahman, R Espinosa, M Meyyappan, CV Nguyen, Field emission properties of carbon nanotube pillar arrays. J Appl Phys 103, 064312 (2008)

190. P Rai, DR Mohapatra, KS Hazra, DS Misra, SP Tiwari, Nanotip formation on a carbon nanotube pillar array for field emission application. Appl Phys Lett 93, (2008). 131921-131921-131923

191. JL Silan, DL Niemann, BP Ribaya, M Rahman, M Meyyappan, CV Nguyen, Carbon nanotube pillar arrays for achieving high emission current densities. Appl Phys Lett 95, 133111 (2009)

192. K Celebi, MT Cole, KBK Teo, HG Park, Observations of early stage graphene growth on copper. Electrochem Solid State Lett 15, K1-K4 (2012)

193. K Celebi, MT Cole, JW Choi, F Wyczisk, P Legagneux, N Rupesinghe, J Robertson, KBK Teo, HG Park, Evolutionary kinetics of graphene formation on copper. Nano Lett 13, 967-974 (2013)

194. H Kim, C Mattevi, MR Calvo, JC Oberg, L Artiglia, S Agnoli, CF Hirjibehedin, M Chhowalla, E Saiz, Activation energy paths for graphene nucleation and growth on Cu. ACS Nano 6, 3614-3623 (2012)

195. C Li, MT Cole, W Lei, K Qu, K Ying, Y Zhang, AR Robertson, JH Warner, S Ding, X Zhang, B Wang, WI Milne, Highly electron transparent graphene for field emission triode gates. Adv Funct Mater 24, 1218-1227 (2014)

196. TB Rymer, PG Hambling, Demountable X-ray tube for crystallography. J Sci Instrum 29, 192 (1952)

197. S Heo, H Kim, J Ha, S Cho, A vacuum-sealed miniature X-ray tube based on carbon nanotube field emitters. Nano Res Lett 7, 1-5 (2012)

198. A Reyes-Mena, C Jensen, E Bard, DC Turner, K Erdmann, Q Qiu, B Gao, J Lu, O Zhou, Miniature X-ray tubes utilizing carbon-nanotube-based cold cathodes. Adv X Ray Anal 48, 204-209 (2005)

199. Y Sakai, A Haga, S Sugita, S Kita, S-I Tanaka, F Okuyama, N Kobayashi, Electron gun using carbon-nanofiber field emitter. Rev Sci Instrum 78, 013305 (2007)

200. W Sugimoto, S Sugita, Y Sakai, H Goto, Y Watanabe, Y Ohga, S Kita, T Ohara, A fine-focusing $X$-ray source using carbon-nanofiber field emitter. J Appl Phys $108,044507(2010)$

201. Y Cheng, J Zhang, YZ Lee, B Gao, S Dike, W Lin, JP Lu, O Zhou, Dynamic radiography using a carbon-nanotube-based field-emission $X$-ray source. Rev Sci Instrum 75, 3264 (2004)

202. J Zhang, G Yang, YZ Lee, S Chang, JP Lu, O Zhou, Multiplexing radiography using a carbon nanotube based $x$-ray source. Appl Phys Lett 89, 064106 (2006)

203. X Qian, R Rajaram, X Calderon-Colon, G Yang, T Phan, DS Lalush, J Lu, O Zhou, Design and characterization of a spatially distributed multibeam field emission $x$-ray source for stationary digital breast tomosynthesis. Med Phys 36, 4389-4399 (2009)

204. Y Sun, DA Jaffray, TW Yeow, The design and fabrication of carbon-nanotubebased field emission X-Ray cathode with ballast resistor. IEEE T Electron Dev 60,7 (2013)

205. J Ryu, J Kang, K Park, Carbon nanotube electron emitter for X-ray imaging. Mater 5, 2353-2359 (2012)

206. Z Liu, G Yang, YZ Lee, D Bordelon, J Lu, O Zhou, Carbon nanotube based microfocus field emission $x$-ray source for microcomputed tomography. Appl Phys Lett 89, 1-3 (2006)

207. SH Heo, HJ Kim, JM Ha, SO Cho, A vacuum-sealed miniature X-ray tube based on carbon nanotube field emitters. Nano Res Lett 7, 5 (2012)

208. J-W Jeong, J-T Kang, S Choi, J-W Kim, S Ahn, Y-H Song, A digital miniature $x$-ray tube with a high-density triode carbon nanotube field emitter. Appl Phys Lett 102, 023504 (2013)

209. P Sarrazin, D Blake, L Delzeit, M Meyyappan, B Boyer, S Snyder, B Espinosa, Carbon-nanotube field emission X-ray tube for space exploration XRD/XRF instrument. Adv X Ray Anal 47, 232-239 (2004)

210. TT Tan, HS Sim, SP Lau, HY Yang, M Tanemura, J Tanaka, X-ray generation using carbon-nanofiber-based flexible field emitters. Appl Phys Lett $88,103105(2006)$

211. S Kita, Y Watanabe, A Ogawa, K Ogura, Y Sakai, Y Matsumoto, Y Isokane, F Okuyama, T Nakazato, T Otsuka, Field-emission-type $X$-ray source using carbon-nanofibers. J Appl Phys 103, 064505 (2008)
212. J-W Kim, J-W Jeong, J-T Kang, S Choi, S Ahn, Y-H Song, Highly reliable field electron emitters produced from reproducible damage-free carbon nanotube composite pastes with optimal inorganic fillers. Nanotech 25. (2014); doi: 10.1088/0957-4484/25/6/065201

213. C-K Park, J-P Kim, S-J Yun, S-H Lee, J-S Park, Field emission properties of carbon nanotubes grown on a conical tungsten tip for the application of a microfocus x-ray tube. Thin Solid Films 516, 304-309 (2007)

214. K Teo, M Chhowalla, G Amaratunga, W Milne, G Pirio, P Legagneux, F Wyczisk, D Pribat, D Hasko, Field emission from dense, sparse, and patterned arrays of carbon nanofibers. Appl Phys Lett 80, 2011-2013 (2002)

215. V Merkulov, D Lowndes, Y Wei, G Eres, E Voelkl, Patterned growth of individual and multiple vertically aligned carbon nanofibers. Appl Phys Lett 76, 3555-3557 (2000)

216. MK Debe, Field emission device having nanostructured emitters. Google Patents, 1998

217. PR Schwoebel, JM Boone, Stationary x-ray source for tomographic medical imaging, 2006. 61423N-61423N-61423

218. E Minoux, O Greening, KBK Teo, SH Dalai, L Gangloff, JP Schnell, L Hudanski, IYY Bu, P Vincent, P Legagneux, GAJ Amaratunga, WI Milne, Achieving high-current carbon nanotube emitters. Nano Lett 5, 2135-2138 (2005)

219. R Forman, Evaluation of the emission capabilities of Spindt-type field emitting cathodes. Appl Surface Sci 16, 277-291 (1983)

220. J-M Bonard, C Klinke, KA Dean, BF Coll, Degradation and failure of carbon nanotube field emitters. Phys Rev B 67, 115406 (2003)

221. WI Milne, KBK Teo, GAJ Amaratunga, P Legagneux, L Gangloff, JP Schnell, V Semet, VT Binh, O Groening, Carbon nanotubes as field emission sources. J Mater Chem 14, 933-943 (2004)

222. C Spindt, I Brodie, L Humphrey, E Westerberg, Physical properties of thin-film field emission cathodes with molybdenum cones. J Appl Phys 47, 5248-5263 (2008)

223. M Doytcheva, M Kaiser, J Nd, In situ transmission electron microscopy investigation of the structural changes in carbon nanotubes during electron emission at high currents. Nanotech 17, 3226 (2006)

224. S Itoh, Current status of the Spindt-type field emitter. Proc ISDEIV 2, 875-876 (2006)

225. C Li, Y Zhang, M Mann, P Hiralal, HE Unalan, W Lei, BP Wang, DP Chu, D Pribat, GAJ Amaratunga, WI Milne, Stable, self-ballasting field emission from zinc oxide nanowires grown on an array of vertically aligned carbon nanofibers. Appl Phys Lett 96, 143114 (2010)

226. Y Liu, L Gao, A study of the electrical properties of carbon nanotube-NiFe $<$ sub $>2</$ sub $>0<$ sub $>4</$ sub $>$ composites: effect of the surface treatment of the carbon nanotubes. Carbon 43, 47-52 (2005)

227. J Madsen, Focal spot size measurements for microfocus X-ray sets. NDT Int 22, 292-296 (1989)

228. W Ehrenberg, WE Spear, An electrostatic focusing system and its application to a fine focus X-Ray tube. Proc Phys Soc B 64, 67 (1951)

229. BM Moores, P Brubacher, Focal spot studies and electron focusing in a demountable X-ray tube. Phys Med Biol 19, 605 (1974)

230. ASfTaM Philadelphia, Standard test method for measurement of focal spots of industrial X-Ray tubes by pinhole imaging. Annual Book ASTM Stand (2010). ASTM-E-1165-12, Volume 03.03; doi: 10.1002/adom.201400238

231. Z Liu, J Zhang, G Yang, Y Cheng, O Zhou, J Lu, Development of a carbon nanotube based microfocus $x$-ray tube with single focusing electrode. Rev Sci Instrum 77, 054302-054306 (2006)

232. S Sultana, X Calderón-Colón, G Cao, O Zhou, J Lu, Design and characterization of a carbon-nanotube-based micro-focus $x$-ray tube for small animal imaging, 2010. pp 76225G-76225G-76229

233. P Legagneux, P Ponard, L Gangloff, S Xavier, C Bourat, J Martinez, CS Cojocaru, A Gohier, JP Mazellier, JP Schnell, D Pribat, KBK Teo, Carbon nanotube photocathodes for optically driven multiple $X$-ray sources. http://www.phantomsnet.net/imaginenano/Abstracts/Nanospain2011 Legagneux_Pierre_pierre.legagneux@thalesgroup.com_Imaginenano2011_ Abstract_Legagneux.pdf

234. X Qian, A Tucker, E Gidcumb, J Shan, G Yang, X Calderon-Colon, S Sultana, J Lu, O Zhou, D Spronk, F Sprenger, Y Zhang, D Kennedy, T Farbizio, Z Jing, High resolution stationary digital breast tomosynthesis using distributed carbon nanotube x-ray source array. Med Phys 39, 2090-2099 (2012)

235. SX Chang, O Zhou, Carbon Nanotubes Field Emission X-ray for Research and Clinical Applications in Radiation Oncology (University of North Carolina, Chapel Hill). http://amos3.aapm.org/abstracts/pdf/77-22629-310436-91429. pdf [Online], (accessed 19/08/2014, 2014) 
236. J Zhang, G Yang, YZ Lee, Y Cheng, B Gao, Q Qiu, JP Lu, O Zhou, A multi-beam $x$-ray imaging system based on carbon nanotube field emitters, 2006. pp 614204-614204-614208

237. G Yang, R Rajaram, G Cao, S Sultana, Z Liu, D Lalush, J Lu, O Zhou, Stationary digital breast tomosynthesis system with a multi-beam field emission x-ray source array, 2008, pp. 69131A-69131A

238. J Shan, P Chtcheprov, AW Tucker, YZ Lee, X Wang, D Foos, MD Heath, J Lu, O Zhou, Stationary chest tomosynthesis using a CNT X-ray source array, 2013. pp 86680E-86680E-86612

239. E Quan, DS Lalush, Three-dimensional imaging properties of rotation-free square and hexagonal micro-CT systems, 2009. pp 725801-725801-72510

240. IA Guzilov, KV Kuzmich, OY Maslennikov, EV Smirnova, PV Minakov, AY Poroykov, AT Rakhimov, B Seleznev, W Sen, Multi beam X-ray tube with the field emitter on the base of nanocrystalline graphite for computer tomography, in Vacuum Electronics Conference, 2009. IVEC '09. IEEE International, 2009, pp. 289-291

241. F Sprenger, X Calderon-Colon, Y Cheng, K Englestad, J Lu, J Maltz, A Paidi, X Qian, D Spronk, S Sultana, G Yang, O Zhou, Distributed source x-ray tube technology for tomosynthesis imaging, 2010, pp. 76225M-76225M

242. Source 1 X-ray. (2000). http://www.source1xray.com/index-2.html

243. Amptek miniature X- Ray source. (2013), http://www.amptek.com/products/ mini-x-ray-tube/

244. J-T Kang, J-W Kim, JW Jeong, S Choi, J Choi, S Ahn, Y-H Song, Analysis of failure in miniature $X$-ray tubes with gated carbon nanotube field emitters. ETRI J 35, 1164-1167 (2013)

245. J Mazellier, Carbon nanotubes based photocathodes for multisource X-Ray generators, 220-223. http:/www.nsti.org/procs/Nanotech2012v1/3/X2.123

246. P Legagneux, Carbon nanotube cathodes for microwave and X-ray electron tubes, in Vacuum Electron Sources Conference and Nanocarbon (IVESC), 2010 8th International (IEEE, New York, 2010), pp. 86-86

247. Siemens, Siemens CNT X-ray [Online], 2010. http://ragingbull.com/forum/ topic/857725

248. Xintek, Nanotechnology Innovations [Online], 2014. http://www.xintek.com/ cnt-x-ray-sources/

\section{Submit your manuscript to a SpringerOpen ${ }^{\circ}$ journal and benefit from:}

- Convenient online submission

- Rigorous peer review

- Immediate publication on acceptance

- Open access: articles freely available online

- High visibility within the field

- Retaining the copyright to your article

Submit your next manuscript at $\gg$ springeropen.com 